\title{
Cell density ratios in a foveal patch in macaque retina
}

\author{
KAREEM M. AHMAD, ${ }^{1}$ KARL KLUG, ${ }^{2}$ STEVE HERR, ${ }^{1}$ PETER STERLING,${ }^{3}$ AND STAN SCHEIN ${ }^{1,2}$ \\ ${ }^{1}$ Department of Psychology, Franz Hall, UCLA, Los Angeles \\ ${ }^{2}$ Brain Research Institute, UCLA, Los Angeles \\ ${ }^{3}$ Department of Neuroscience, University of Pennsylvania, Philadelphia \\ (Received August 26, 2002; AcCePted March 25, 2003)
}

\begin{abstract}
We examine the assumptions that the fovea contains equal numbers of inner (invaginating or ON) and outer (flat or OFF) midget bipolar cells and equal numbers of inner and outer diffuse bipolar cells. Based on reconstruction from electron photomicrographs of serial thin sections through the fovea of a macaque monkey, we reject both assumptions. First, every foveal $\mathrm{L}$ and $\mathrm{M}$ cone is presynaptic to one inner and one outer midget bipolar cell; however, $\mathrm{S}$ cones are presynaptic to one outer but no inner midget bipolar cell. Second, we measure the density of all foveal cells in the same patch of fovea, affording accurate cell density ratios. For each foveal cone pedicle, at a density of $26,500 \mathrm{~mm}^{-2}$, there is close to one $(0.88)$ outer diffuse bipolar cell but only 0.40 inner diffuse bipolar cells. This asymmetry may be related to differences in resolution and sensitivity for light increments and decrements. We also find one (1.01) Müller cell, one (1.01) amacrine cell in the inner nuclear layer, and close to one $(0.83)$ horizontal cell for each cone pedicle. In addition, for each S cone, there are two inner S-cone bipolar cells and two small bistratified ganglion cells. In total, there are 3.4 cone bipolar cells per cone but only 2.6 ganglion cells per cone. The latter ratio is enough to accommodate one midget ganglion cell for each midget bipolar cell.
\end{abstract}

Keywords: Fovea, Cones, Bipolar cells, Amacrine cells, Horizontal cells, Ganglion cells

\section{Introduction}

The central area of the primate retina, the fovea, supports the finest acuity, the result of dense packing of cone photoreceptors and associated postreceptoral cells. This region is less complicated than peripheral retina because it has very few rod photoreceptors and rod-specific circuits. In addition, it has long been believed that there is exactly one inner (or invaginating or ON) midget bipolar cell and one outer (or flat or OFF) midget bipolar cell for each foveal cone (Kolb, 1970) and one midget ganglion cell for each foveal midget bipolar cell (Polyak, 1941; Boycott \& Dowling, 1969; Kolb \& DeKorver, 1991; Calkins et al., 1994). (Because our investigation is anatomical, we follow Dacey (1993b) in referring to bipolar cells as inner or outer, terms that refer to their termination in the inner (ON or $b$ ) or outer (OFF or $a$ ) sublamina of the inner plexiform layer (IPL) (Famiglietti \& Kolb, 1976, Nelson et al., 1978; Boycott \& Hopkins, 1993).) Based on ultrastructural evidence of cone to bipolar cell connectivity, we confirm this picture for foveal midget circuits driven by $\mathrm{L}$ and $\mathrm{M}$ cones, leading to the conclusion that the sampling density of foveal cones and thus acuity is preserved in both ON and OFF midget pathways. However, we modify this description for foveal midget circuits driven by $\mathrm{S}$ cones.

Address correspondence and reprint requests to: Stan Schein, Department of Psychology, Franz Hall, Mailcode 951563, UCLA Los Angeles, CA, 90095-1563, USA. E-mail: schein@ucla.edu
Such a simple one-for-oneness is not generally supposed for other cells in the fovea, but there are numbers in some reports that hint at this possibility for diffuse bipolar cells and cones (Boycott \& Wässle, 1991), for Müller cells and cones (Distler \& Dreher, 1996; Burris et al., 2002), and for Müller cells and amacrine cells in the inner nuclear layer (Martin \& Grünert, 1992). To test this possibility, we identify every cell from a large series of thin sections through a region of the fovea and determine ratios of cell densities for these and other groups of foveal cell. To take full advantage of our limited sample, we use a novel method of calculating cell density. We find that integer density ratios in the fovea are more common than previously realized, perhaps reflecting a simple developmental plan. One exception to this "rule" is the group of inner diffuse bipolar cells, whose density is substantially less than that of the group of outer diffuse bipolar cells, whose density is nearly one for each cone. This exception may be related to psychophysical evidence of asymmetries in response to light increment and light decrement.

\section{Materials and methods}

\section{Tissue preparation and electron microscopy}

Tissue preparation is described in earlier papers that examined the same series of electron photomicrographs (Tsukamoto et al., 1992; Calkins et al., 1994). The procedures were approved by the Animal Care and Use Committee at the Massachusetts Eye and Ear 
Infirmary of Harvard University. A series of 319 consecutive, vertical sections was cut at $90-\mathrm{nm}$ thickness along the horizontal meridian and stained. The $160-\mu \mathrm{m}$ wide region from $480 \mu \mathrm{m}$ to $640 \mu \mathrm{m}$ nasal to the center of the retina was photographed in an electron microscope en montage at $400 \times$ and $2000 \times$ and then printed with $2.5 \times$ enlargement to give print magnifications of $1000 \times$ and $5000 \times$. (Nonetheless, these will be referred to as $400 \times$ and $2000 \times$ photomicrographs.) The outer plexiform layer (OPL) over the whole region and much of the inner plexiform layer (IPL) were rephotographed at $5000 \times$ and printed with $3.5 \times$ enlargement $(17,500 \times$ prints). Selected photoreceptor terminals were also rephotographed at $10,000 \times$ and enlarged. The $400 \times$ photomicrographs extended further on both sides of this $160-\mu \mathrm{m}$ wide region. The electron photomicrographs in Figs. 1 and 2 were scanned with an Agfa scanner into Adobe Photoshop 5.0. Because relative electron density was of interest (Dense vs. Pale), no retouching or other image manipulation, including adjusting for brightness and contrast, was performed. The electron micrographs in Fig. 6 were scanned with a Canon N1240V scanner into ArcSoft Photostudio 4.1.2c 2000, but linear remapping of brightness and contrast was applied to optimize visualization of membrane densities. Because of lateral displacement of cone pedicles from cone inner segments, the center of the region corresponded to $\sim 1 \mathrm{deg}$ of eccentricity (Calkins et al., 1994). The fovea in Macaque has a radius of $500 \mu \mathrm{m}$, or $2.5 \mathrm{degs}$, so the photoreceptors that contacted this region were well within the fovea (Polyak, 1941).

\section{Identification of retinal cells}

We identified all photoreceptor terminals and cells in the inner nuclear layer (INL) and ganglion cell layer (GCL) of our material (Fig. 1). Nearly all of the photoreceptor synaptic terminals were cone pedicles $(\mathbf{P})$, but there were several rod spherules as well.

Horizontal cells $(\mathbf{H})$ had dendrites that supplied lateral elements of triads in cone pedicles and had no process that terminated in the inner plexiform layer (IPL). They had a distinctive, pale, mitochondria-filled "cap" at the top of their somas and formed the outermost sublayer of somas in the INL.

Müller cells (*) were distinguished by their dense, polygonal somas. Most were located between the INL amacrine cell somas (A) and the bipolar cell somas (Bip). Each Müller cell had one "outer trunk" (Burris et al., 2002) in the OPL, just below the cone pedicles.

Within the INL, amacrine cell somas were located between the Müller cell sublayer and the IPL. Although the amacrine cell sublayer was usually one cell thick, in a given photomicrograph a few somas appeared in a second sublayer; the latter somas generally reached the border of the IPL in other sections. They were positively identified by having a single process that left the soma and terminated in the IPL.

Because the $400 \times$ photomicrographs extended beyond the boundaries of the $2000 \times / 5000 \times($ enlarged $2.5 \times / 3.5 \times$ ) material, we were able to include cells beyond those boundaries in maps of cone pedicles, horizontal cells, and INL amacrine cells. Those cells were identified by their location and appearance.

Most of the cells in the INL were bipolar cells. We identified these by tracking branches from the soma outward to their contacts with cone pedicles in the OPL and inward to their terminals in the IPL within the $2000 \times / 5000 \times$ region. Midget bipolar cells $(+\mathbf{M}$ and $\mathbf{- M}$ in Fig. 1B) were contacted by a single cone pedicle, although a few received a small number of contacts from a second cone pedicle. By contrast, diffuse bipolar cells $(+\mathbf{D}$ and $-\mathbf{D}$ in
Fig. 1B) were contacted by at least six and as many as 12 contiguous cone pedicles, including $\mathrm{S}$-cone pedicles. The main dendrite of a midget bipolar cell branched directly under its cone pedicle, whereas the main dendrite of a diffuse bipolar cell branched at the INL/OPL border. Inner S-cone bipolar cells $(+\mathbf{S}$ in Fig. 1B) were contacted by multiple, widely spaced S-cone pedicles (Mariani, 1984; Kouyama \& Marshak, 1992; Dacey, 1993a). Like diffuse bipolar cells, their main dendrites branched at the INL/ OPL border. None of four rod bipolar cell somas appeared in Fig. 1. We found no giant bistratified bipolar cells (Mariani, 1983) in our series.

We tracked many bipolar cells to their terminals in the outer ( $a$ or OFF) or inner ( $b$ or ON) half of the IPL (Fig. 2). The synaptic terminal of one bipolar cell often appeared in several pieces in any given photomicrograph. We also designated each bipolar cell as "+" or " - ," based on whether the cell (dendrites, soma, and terminal) was dense $(+)$ or pale $(-)$ in appearance (Figs. 1 \& 2). Thus, the plus in the labels $+\mathbf{M},+\mathbf{D}$, and $\mathbf{+ S}$ referred to dense midget, diffuse, and inner S-cone bipolar cells, and the minus in the labels $\mathbf{- M}$ and $\mathbf{- D}$ referred to pale midget and diffuse bipolar cells. We demonstrate the correspondence between dense $(+)$ and inner and between pale (-) and outer in Results.

We also counted all the cells in the ganglion cell layer (GCL). Five percent of foveal GCL cells have been reported to be displaced amacrine cells (Wässle et al., 1990; Sjöstrand et al., 1999), but we ourselves did not distinguish them from ganglion cells in the ganglion cell layer.

\section{Coordinates of cells}

To measure the density of cone pedicles, we digitized the raw $X, Y$, and $Z$ coordinates of each pedicle. We numbered sections from 1 to 319 , spaced at $0.09 \mu \mathrm{m}$. For a cone pedicle entirely within the series, the average of its first and last sections (the center section) determined its $Z$ coordinate (in $\mu \mathrm{m}$ ) by the formula: $28.71-0.09$ * (center section number). (Sections are $0.09 \mu \mathrm{m}$ thick. The negative sign in the formula provides a $Z$ coordinate that obeyed the right-hand rule, with $X$ in a photograph increasing from left to right and $Y$ increasing from bottom to top. The starting value, $28.71 \mu \mathrm{m}$, was calculated from 319 sections $* 0.09 \mu \mathrm{m} \mathrm{section}^{-1}$.) The average number of sections that a cone pedicle or cell soma spans was measured for all complete individuals of each type in the series of 319 sections (Table 1). For a pedicle that was only partially within the series, we identified its center section as its end section within the series plus or minus half of the average span of a pedicle, 80.3 sections (Table 1 ).

From photomicrographs of every fifth section, we drew outlines of numerous structures, including blood vessels and cells, and registered the transparent plastic sheets with one another to create a stack. From the center section of a given pedicle, which established its raw $Z$ coordinate, we digitized its raw $X$ and $Y$ coordinates by marking the center of the pedicle on the nearest plastic sheet and digitizing that point into the Montage program (Smith, 1987). Fig. 3A, the left column of Fig. 3, shows (most of) these pedicle centers projected into the $Y-Z, Y-X$, and $Z-X$ planes. Because the equation listed above for converting section number to a raw $Z$ coordinate subtracts the product of 0.09 and section number, the $Z$ axis in Fig. 3 is inverted compared to previously published maps (e.g. Tsukamoto et al., 1992).

To measure the density of horizontal, inner midget bipolar, outer midget bipolar, Müller, and INL amacrine cell somas, we obtained raw $X, Y$, and $Z$ coordinates as we did for pedicles, except 


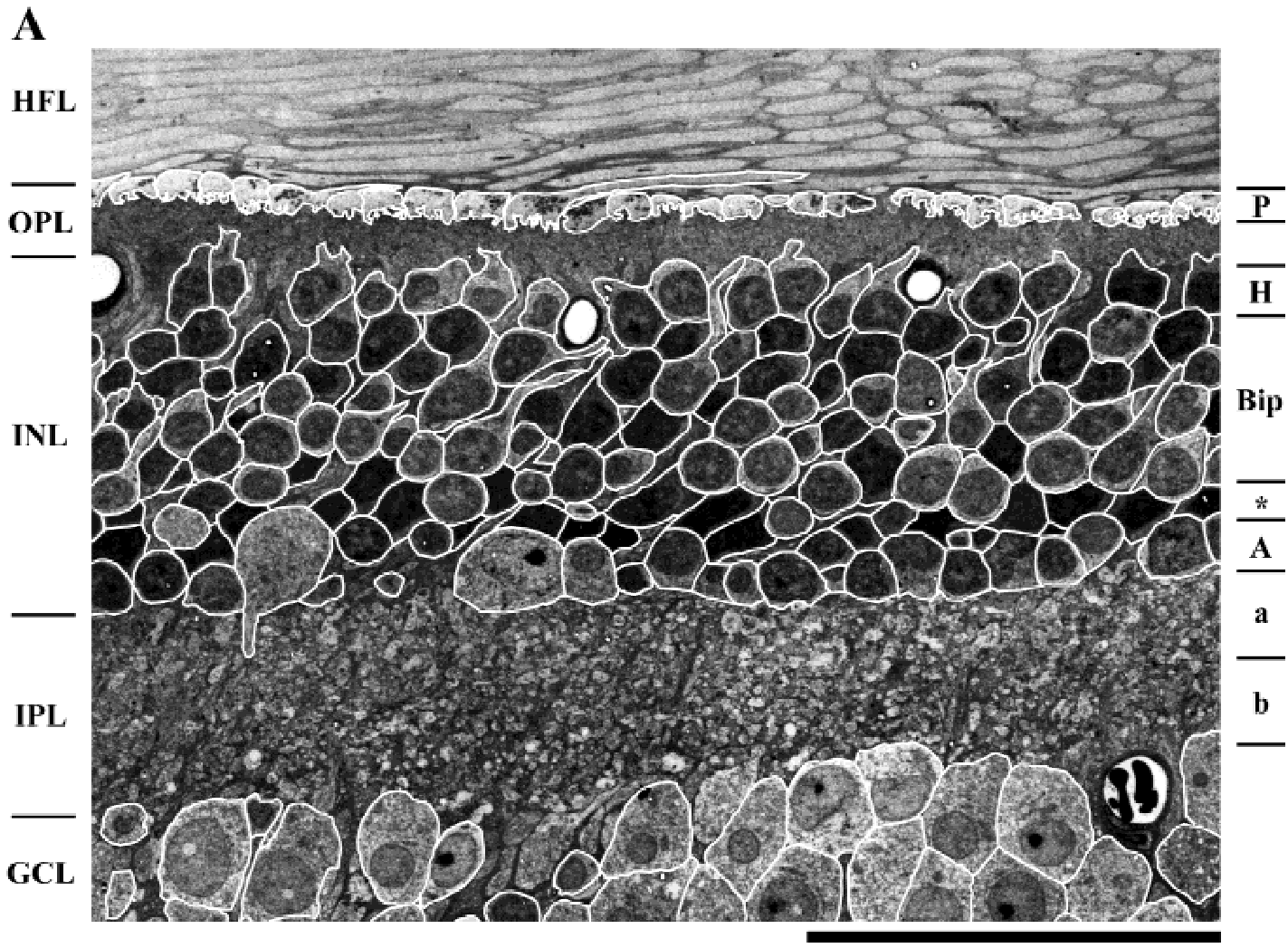

B
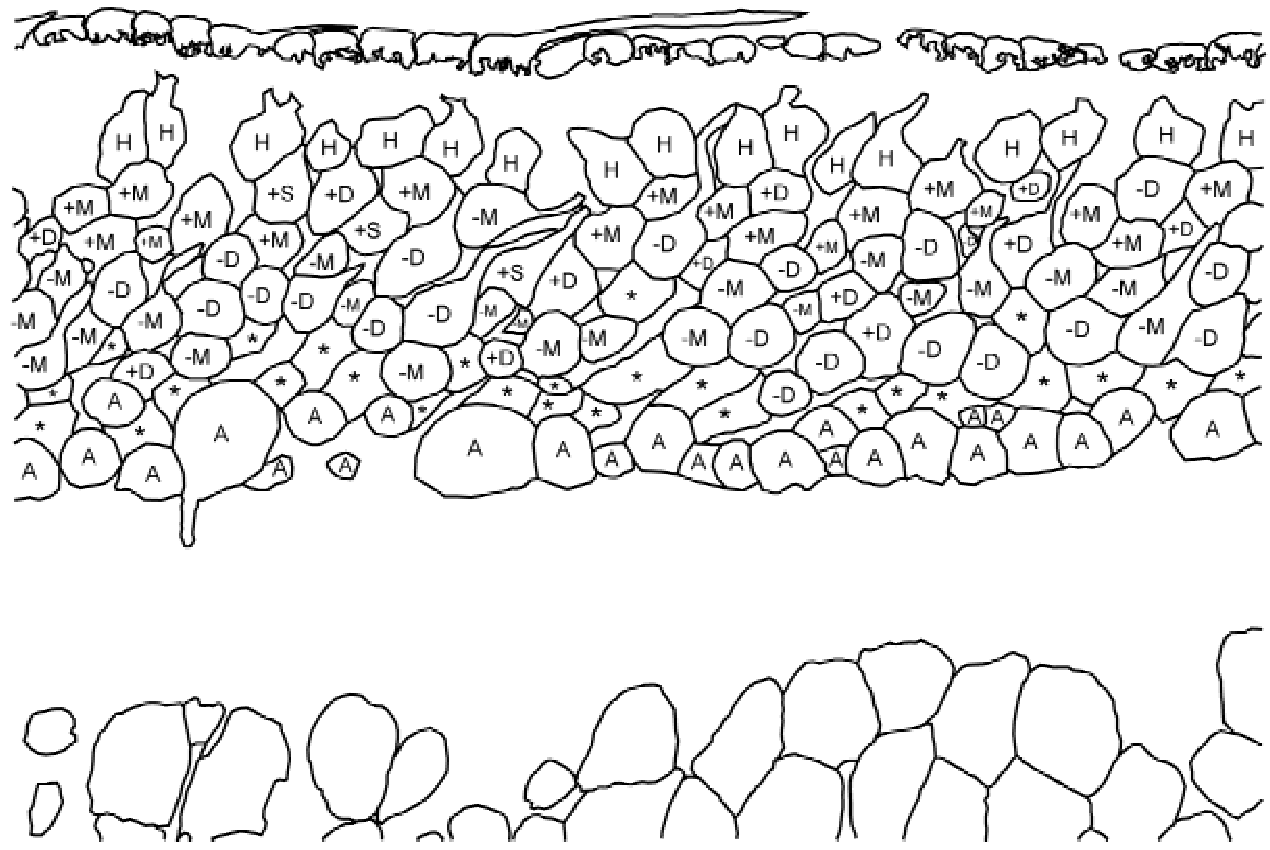

Fig. 1. Macaque monkey fovea. A: Cross section. This electron photomicrograph is centered $575 \mu \mathrm{m}$ from the center of the retina, along and aligned with the nasal horizontal meridian. Because of lateral displacement of cone pedicles from cone inner segments, the center corresponds to $\sim 1$ deg of eccentricity. The photomicrograph, originally photographed at $400 \times$ and printed at $1000 \times$, shows part of one of the 319 serial sections that we used to track and identify cell somas and cone pedicles, generally from enlargements of higher magnification photomicrographs, and to calculate the $X, Y$, and $Z$ coordinates of their centers. Identification of cells is described in the text. We outline the somas in the inner nuclear and ganglion cell layers and the cone pedicles. Layers are labeled along the left: HFL (Henle fiber layer), OPL (outer plexiform layer), INL (inner nuclear layer), IPL (inner plexiform layer), and GCL (ganglion cell layer). Sublayers are labeled along the right: P (pedicles), H (horizontal cells), Bip (bipolar cells), * (Müller cells), A (amacrine cells), a (outer half of IPL), and b (inner half of IPL). Scale bar $=50 \mu \mathrm{m}$. B: Overlay. The $+/-$ designation in bipolar cells denotes the dense/pale appearance of their somas, which we marked after examination over several photomicrographs. This region contains $18+\mathbf{M}$ (dense, midget bipolar cell), $22-\mathbf{M}$ (pale, midget bipolar cell), $12+\mathbf{D}$ (dense, diffuse bipolar cell), $18-\mathbf{D}$ (pale, diffuse bipolar cell), and $2+\mathbf{S}$ (dense, inner S-cone bipolar cell). Other cells are also labeled: $27 \mathbf{P}$ (pedicles), $17 \mathbf{H}$ (horizontal cells), $26 *$ (Müller cells), and $27 \mathbf{A}$ (amacrine cells). 

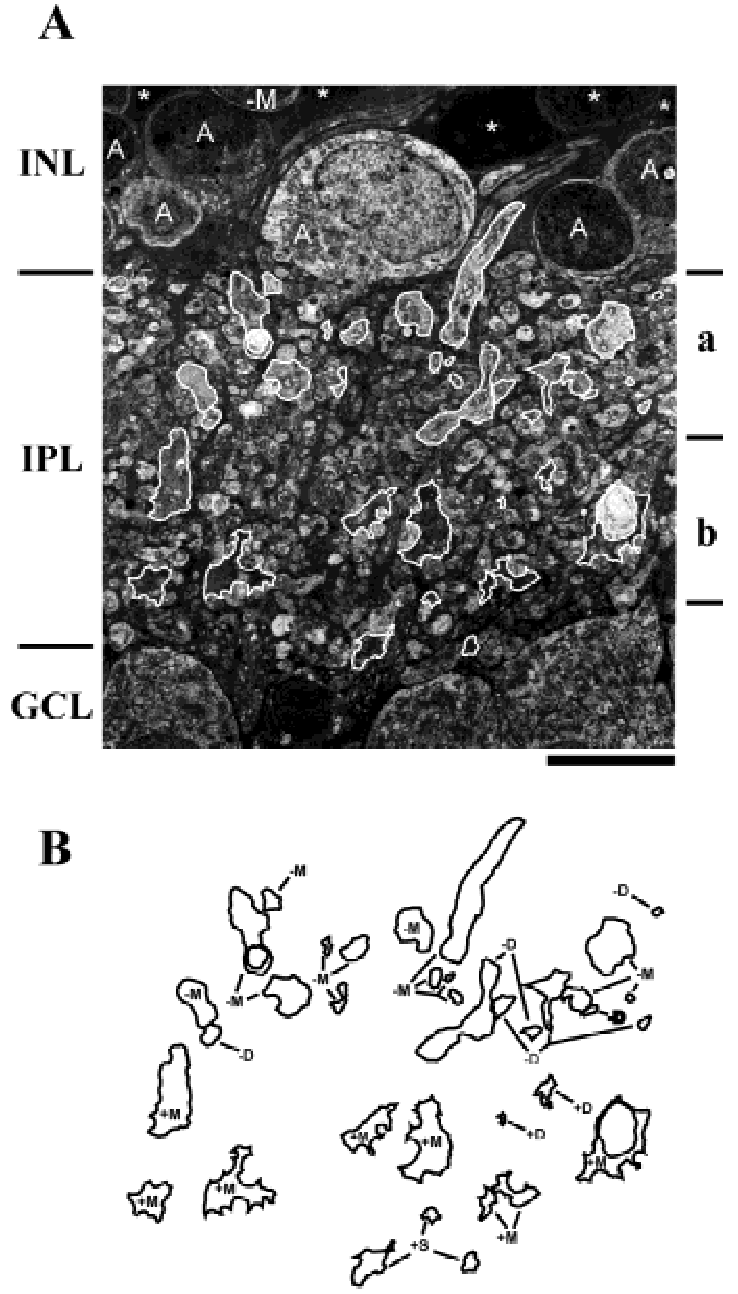

Fig. 2. Bipolar terminals in the IPL. A: Electron photomicrograph. The bipolar terminals in the photomicrograph, originally photographed at $2000 \times$ and printed at $5000 \times$, are outlined for clarity and identified in the overlay in Fig. 2B. Cell bodies are labeled as in Fig. 1B. Layers are labeled along the left: INL (inner nuclear layer), IPL (inner plexiform layer), and GCL (ganglion cell layer). Sublayers are labeled along the right: a (outer half of IPL), and b (inner half of IPL). Scale bar $=2 \mu \mathrm{m}$. B: Overlay. To identify each bipolar terminal, we tracked it to its soma and then to its dendritic contacts in electron photomicrographs originally photographed at $5000 \times$ and printed at $17,500 \times$. We designate each of these terminals, some of which are in several parts, with one letter preceded as "+" or "-" from the dense or pale appearance of its soma (as can be seen in Fig. 1A), dendrites, and terminal (as can be seen in part A of this figure). This region of IPL contains $7+\mathbf{M}$ (dense, midget), $7-\mathbf{M}$ (pale, midget), $1+\mathbf{S}$ (dense, inner S-cone), $2+\mathbf{D}$ (dense, diffuse), and $5-\mathbf{D}$ (pale, diffuse) bipolar terminals.

that the average span of complete objects was different for each group of cell (Table 1). For GCL cells, we obtained coordinates for the center of their nucleolus or the center of the nucleus in the few cases in which there were two nucleoli.

We digitized the locations of OPL trunks of Müller cells because they were in the same layer as cone pedicles and were thus better than the somas for density comparison (Burris et al., 2002). We digitized the locations of the main dendrites of inner diffuse, outer diffuse, inner S-cone, and rod bipolar cells at the INL/OPL border because these cells' somas were often far from the centers of their dendritic fields. Also, their main dendrites were closer to pedicles, which afforded better density comparisons. Since main dendrites and Müller cell trunks spanned just a few sections, we did not have to calculate the centers of partial objects of those groups of cell.

\section{Rotation of points into a hypothetical horizontal section}

To compare densities of different types of cell, density measurements should be made from arrays of center points in the same plane, for example, the horizontal plane. Cone pedicle centers define the horizontal $(Z-X)$ plane, so the projection of center points of pedicles should appear as a narrow, horizontally oriented line of points in the $Y-Z$ and $Y-X$ planes, as is shown in the graphs along the right side of Fig. 3 .

The projections of the raw coordinates of pedicle center points into the $Y-Z$ and $Y-X$ planes (top two graphs of Fig. 3A) demonstrate that the cloud of points was not in the horizontal plane. This was so for two reasons. First, the sections were cut at a slight angle to the vertical, so the centers of pedicles rose (in $Y$ ) with the decrease in $Z$ from section \#1 to section \#319 (cf. Raw $Y$ vs. Raw $Z$ plot in Fig. 3A). Second, it was not possible to know beforehand how to orient each photomicrograph so that the pedicles formed a horizontal row in each photomicrograph. (The actual departure from horizontal is exaggerated in the Raw $Y$ vs. Raw $X$ plot in Fig. 3A because the scales of the two axes are different.)

Two rotations were needed to take the cloud of pedicle centers represented by the schematic in Fig. 3A into the horizontal $(X-Z)$ plane, that is, to transform the coordinates from Fig. 3A into those in Fig. 3C. First, the cloud of points, schematized by the block in the top part of Fig. 3A, was rotated around the $X$-axis to give the projections in Fig. 3B. Second, this rotated cloud of points was rotated around the $Z$-axis to give the projections in Fig. 3C. For all the other retinal cells for which we wished to determine cell density, we used the same rotations on their clouds of center points.

After rotation, we computed the average depth ( $Y$-position) of various cell groups in the retina relative to cone pedicles (Table 1).

\section{Areal density of cells}

Fig. 4 illustrates how we determined (1) the center, (2) extent of the region of a horizontal array of points over which we measured areal density (or simply, density), and (3) how we calculated density by a regression method. The center of a small starting box was positioned midway between the largest and smallest $X$ coordinates and midway between the largest and smallest $Z$ coordinates within each array of points. Points were counted within counting boxes whose aspect ratio was equal to the span of $Z$ that included all of the points divided by the span of $X$ that included all of the points; for pedicles, the aspect ratio was 0.187 . The counting boxes increased in size from the starting box, $20 \mu \mathrm{m}$ wide by $(0.187 \times$ $20 \mu \mathrm{m}=) 3.74 \mu \mathrm{m}$ high, through larger boxes that increased in width by $2-\mu \mathrm{m}$ increments and in height by $(0.187 \times 2 \mu \mathrm{m}=)$ $0.374-\mu \mathrm{m}$ increments. (For illustration purposes, Fig. 4A shows only some of the counting boxes.) The best counting box was called the measurement box. Fig. 4B shows three (among many) candidate measurement boxes. We wished to determine which candidate was the best and thus the measurement box.

The graphs in Fig. 4C show the number of pedicles versus counting box area for counting boxes whose size increased up to candidate measurement boxes 1,2 , and 3 . For each of these candidate measurement boxes, the slopes of best-fitting lines through 
Table 1. Span and depth of complete objects ${ }^{\mathrm{a}}$

\begin{tabular}{lccccc}
\hline \hline Cell group & Number & $\begin{array}{c}\text { Span }(Z) \\
(\text { sections })\end{array}$ & $\begin{array}{c}\text { Span }(Z) \\
(\mu \mathrm{m})\end{array}$ & $\begin{array}{c}\text { Final } Y \text { coordinate } \\
(\mu \mathrm{m})\end{array}$ & $\begin{array}{c}\text { Relative position } \\
(\mu \mathrm{m})\end{array}$ \\
\hline Cone pedicles & 121 & $80.3 \pm 9.2$ & $7.2 \pm 0.8$ & $65.4 \pm 1.3$ & $0.0 \pm 1.3$ \\
Horizontal cell somas & 110 & $72.2 \pm 9.8$ & $6.5 \pm 0.9$ & $53.9 \pm 2.0$ & $11.6 \pm 2.0$ \\
Inner midget bipolar cell somas & 76 & $60.4 \pm 5.3$ & $5.4 \pm 0.5$ & $47.7 \pm 2.7$ & $17.8 \pm 2.7$ \\
Outer midget bipolar cell somas & 72 & $69.2 \pm 6.2$ & $6.2 \pm 0.6$ & $38.2 \pm 4.8$ & $27.2 \pm 4.8$ \\
Müller cell somas & 75 & $62.9 \pm 7.0$ & $5.7 \pm 0.6$ & $30.5 \pm 4.3$ & $34.9 \pm 4.3$ \\
INL Amacrine cell somas & 114 & $78.9 \pm 14.8$ & $7.1 \pm 1.3$ & $24.0 \pm 3.5$ & $41.4 \pm 3.5$ \\
GCL cell somas & 298 & & & $-34.2 \pm 17.1$ & $99.6 \pm 17.1$ \\
\end{tabular}

${ }^{a}$ Values after \pm signs represent one standard deviation.

the origin were different, and the slopes of the lines had different standard errors. The slopes, rounded to the nearest integer, are expressed in cells $\mathrm{mm}^{-2}$ and correspond to a cell density for that candidate measurement box. (Because the points are not independent measurements, the standard error of the slope conveys the precision of the fit of the slope of the line through the points; however, it is not a statistical measure of the precision of the density measurement.) Slopes (diamonds in Fig. 4D) and standard errors of the slopes (circles in Fig. 4E) are shown as a function of candidate measurement box area.

Simple calculations of density, obtained by dividing the number of points by the area of a counting box, are shown by the squares in Fig. 4D. For small boxes, these simple density values varied wildly, partly due to the small number of data points and partly due to jumps each time the area increased to admit new points. For larger boxes, the simple density value and the slope of the regression line converged. For very large boxes, the simple values dropped below the regression slopes when the box exceeded the region over which we had exhaustively identified points.

Candidate measurement box \#2, with an area of $6345 \mu \mathrm{m}^{2}$, was optimal, because it had the largest area prior to the final, marked divergence of the density calculated by regression $(26,512$ cells $\mathrm{mm}^{-2}$ ) and the simple density $\left(26,162\right.$ cells $\left.\mathrm{mm}^{-2}\right)$, as marked by the asterisk in Fig. 4D. In addition, the measurement box generally had the lowest standard error of the slope, as shown by the asterisk in Fig. 4E. This expanding box method in conjunction with density calculation from the regression slope optimizes the calculation of density for a single, limited sample of points, such as found in datasets produced by reconstruction from electron microscopy.

To estimate the precision of the density measurement, we must compare several independent samples. Therefore, we divide the measurement box into four approximately square, adjacent boxes and compute the simple density for each. The sample standard deviation for these four simple densities was $6.2 \%$ of their mean. Density ratios are much more precise than is reflected by this or the other coefficients of variation, because the positions of cells of different types are directly related, as in the example of cone pedicles and outer midget bipolar cells in (Fig. 5), or less directly but still related, as in the example of cone pedicles and INL amacrine cell somas.

We also applied these methods to compute cell density of horizontal cells, inner and outer midget bipolar cells, inner and outer diffuse bipolar cells, inner S-cone bipolar cells, Müller cells, INL amacrine cells, and GCL cells. There were too few $\mathrm{S}$ cones and rod bipolar cells to apply this method to those cell types.
Therefore, to compute the density of S cones, we subtracted the density of $\mathrm{L} / \mathrm{M}$ cones from the density of All cones, and to compute the density of rod bipolar cells, we subtracted the density of inner S-cone bipolar cells from the density of an array that combined inner S-cone and rod bipolar cells.

\section{Lateral displacement and magnification from cone pedicles to INL and GCL cells}

INL cells that are located further from the center of the retina than their pedicles are described as "laterally displaced" from their pedicles. Radial magnification occurs if the lateral displacement of INL cells increases with increasing eccentricity (or radius from the fovea) (Schein, 1988). The circumference of a circle at the larger eccentricity of the INL cell would be greater than the circumference of a circle at the smaller eccentricity of its pedicle, giving circumferential magnification as well. Areal magnification is the product of linear magnifications in the radial and circumferential directions. Such a magnification can have a substantial effect on interpretation of cell density measurements in the retina. For example, the density of cone inner segments in central-most retina is $\sim 200,000 \mathrm{~mm}^{-2}$, ten times the density of their cone pedicles, $\sim 20,000 \mathrm{~mm}^{-2}$. The ten-fold disparity is the result of the connection of $1 \mathrm{~mm}^{2}$ of cone inner segments to $10 \mathrm{~mm}^{2}$ of cone pedicles (Schein, 1988). Since our patch of retina was on the horizontal meridian, these radial and circumferential directions corresponded to our $X$ and $Z$ directions.

Areal magnification from cone pedicles to postreceptoral cells in the INL should be much less than ten, because a cone pedicle has a large footprint, similar to the size of an INL cell soma, and because cells in the INL are stacked in multiple layers. We were able to measure the areal magnification from pedicles to INL cells very accurately (and thus enable us to compare densities) because we had identified the specific midget bipolar cells that were contacted by each pedicle.

Fig. 5A shows all of the cone pedicles (circles) for which we identified inner midget bipolar cell somas (filled diamonds). Each pedicle-bipolar pair is connected by a line segment. The $X$ coordinate of inner midget bipolar cell somas depended $\left(r^{2}=0.992\right)$ on the $X$ coordinate of their pedicles (Fig. 5B), with a slope of $1.013 \pm 0.011$, which was not statistically significantly different from 1.0, and an intercept (or mean displacement) of just $5.3 \mu \mathrm{m}$. This result indicated that the lateral displacement from pedicles to inner midget bipolar cells did not change significantly along the $X$-axis; therefore, there was neither expansion nor contraction from one to the other in the $X$ (radial) direction. Likewise, the 

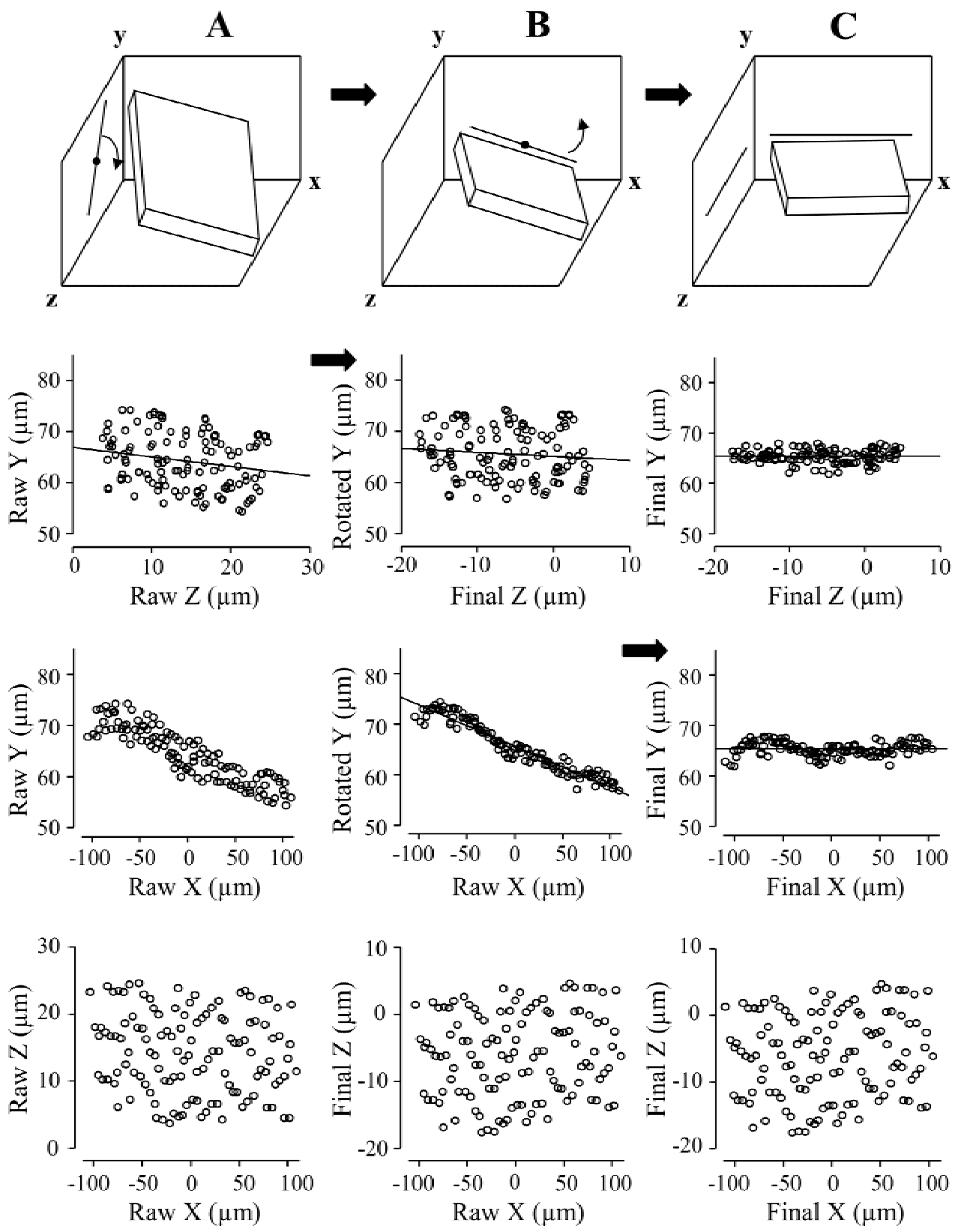

Fig. 3. Rotating the cloud of pedicle centers into the horizontal plane. A: Raw coordinates. The center points of cone pedicles which are entirely within the series of 319 sections are plotted in three graphs on the left: $\operatorname{Raw} Y v s$. Raw $Z$, $\operatorname{Raw} Y v s$. Raw $X$, and $\operatorname{Raw} Z$ $v s$. Raw $X$. The $Z$ axes in the bottom row of graphs are inverted compared to previously published maps (e.g. Tsukamoto et al., 1992). The $X$ axes are preserved, and the $X$ coordinate of the center of the fovea would be approximately $+570 \mu \mathrm{m}$. The cloud of points is shown schematically as a block at the top. The line in the top graph is calculated by linear regression to fit the Raw $Y$-Raw $Z$ coordinates of pedicles. B,C: Coordinates after first (B) and second (C) rotations. The first rotation is specifically about the $X$-axis, the second about the $Z$-axis. The angles of the two rotations are chosen so that the cloud of points in both the final $Y-Z$ and $Y-X$ planes are fit best by horizontal lines. We apply these specific angles of rotation to transform the raw coordinates of all cells in our series to final coordinates.

$Z$ coordinates of inner midget bipolar cells depended $\left(r^{2}=0.851\right)$ on the $Z$ coordinates of their pedicles (see line in Fig. 5E), with a slope of $0.990 \pm 0.052$. Because the patch of retina that we studied was on the horizontal meridian, this slope also gives a direct measurement of circumferential magnification, which was also not significantly different from unity.

For the same reason, that the patch of retina was the on the horizontal meridian, the $X$ coordinate of an inner midget bipolar cells did not depend on the $Z$ coordinate of its pedicle (Fig. 5C; $\left.r^{2}=0.034\right)$, and the $Z$ coordinate of an inner midget bipolar cell did not depend on the $X$ coordinate of its pedicle (Fig. 5D; $r^{2}=$ 0.030 ).

Areal magnification for inner midget bipolar cells, the product of these radial and circumferential linear magnifications, 1.013 and 0.990, was 1.002. The areal magnification for outer midget bipolar cells was also not significantly different from unity. However, the 
A

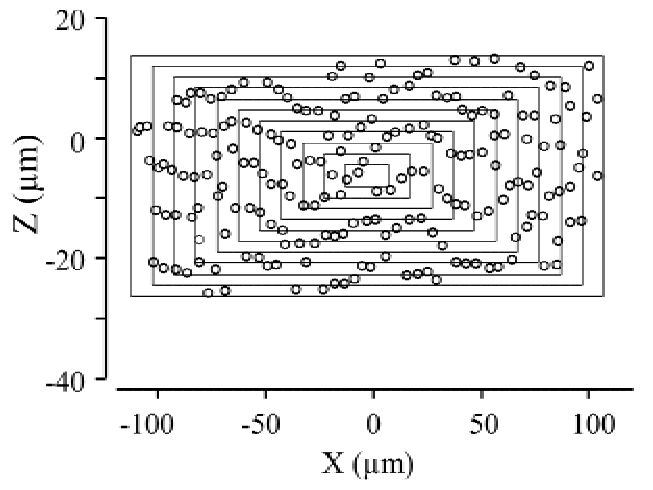

B

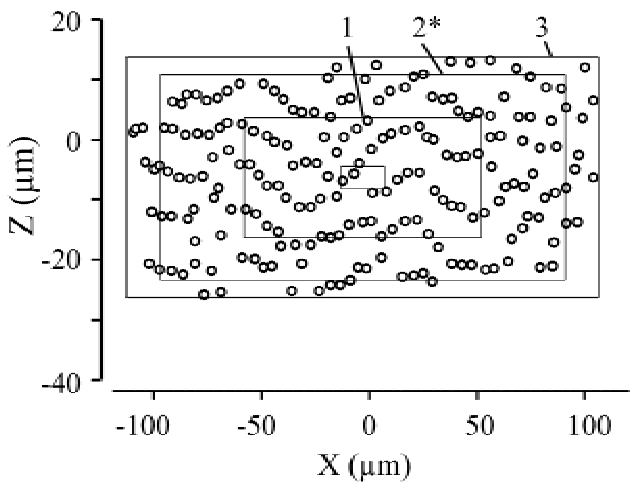

C

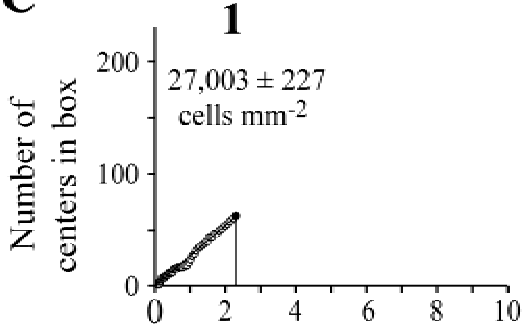

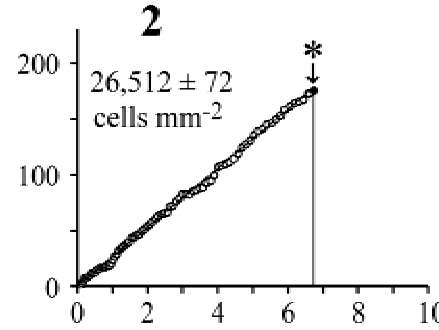

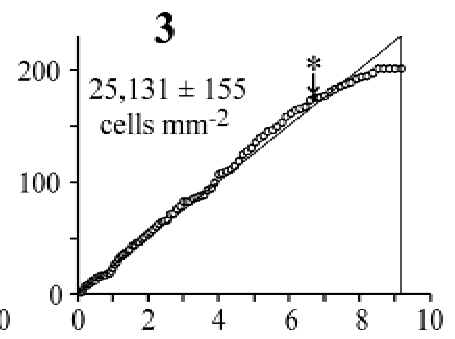

Area of expanding box $\left(\mu \mathrm{m}^{2} \times 1000\right)$

D

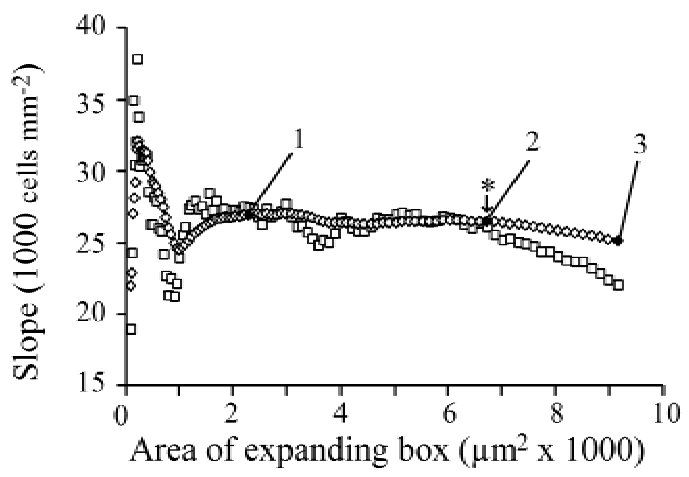

$\mathbf{E}$

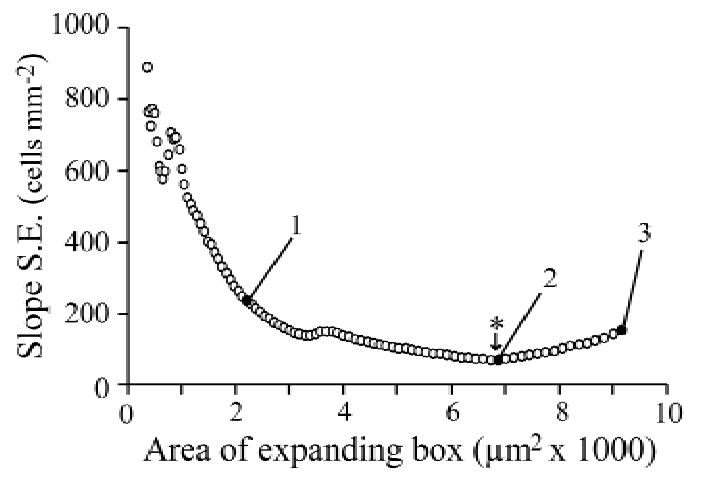

Fig. 4. Measuring pedicle density by the expanding box method. A: A series of counting boxes. All of these boxes are centered at $(-3.021 \mu \mathrm{m},-6.217 \mu \mathrm{m})$, which is midway between the left-most and right-most $X$ coordinates and midway between the highest and lowest $Z$ coordinates of the points. These points represent the centers of pedicles that were entirely within the series (Final $Z$-Final $X$ graph of the pedicle array in Fig. 3C) plus pedicles that were partially within the series. The aspect ratio (0.187) of these boxes is the same as that of the smallest box that includes all of the points. The starting box has a width of $20 \mu \mathrm{m}$. The height of the starting box, $3.74 \mu \mathrm{m}$, is the product of the width $(20 \mu \mathrm{m})$ and the aspect ratio $(0.187)$. Point counts are taken from a series of counting boxes that increase in width by $2-\mu \mathrm{m}$ steps and in height by $0.374-\mu \mathrm{m}(0.187 \times 2 \mu \mathrm{m})$ steps. This figure shows only a few of the counting boxes. Pedicles are shown as disks, but counts are based on (center) points. B: Three examples of candidate measurement boxes. These candidates are too small (\#1) to be the measurement box, optimal (\#2), or too large (\#3), as explained in part D. C: Density calculation. Linear regression is used to find the slope and the standard error of the slope of the line that best fits the series of counts within counting boxes of increasing area, with the line constrained to go through the origin. The slope of the line is the density of points. The counts fall below the line in candidate measurement box \#3, suggesting that this box is too large, that is, larger than the region in which we exhaustively located pedicles. The identification of the correct measurement box, \#2, is described in part D. It is generally the largest one before the counts fall away from the linear regression line. Measurement box \#1 includes too little of the area that is densely sampled and therefore too few points. D: Identification of the measurement box. The diamonds represent slopes of regression lines (densities) as a function of area of candidate measurement box. The slopes corresponding to candidate measurement boxes \#1, \#2, and \#3 are marked. The squares represent simple densities, which are computed by dividing the number of points within each counting box by the area of each counting box. The two density measurements diverge for the last time when the box grows larger than the exhaustively sampled region and begins to contain empty space. This point is marked by an asterisk in the figure and corresponds to measurement box \#2 above. E: Standards errors (SE) of slopes. The SE of the slope generally falls to a minimum for the measurement box chosen as the correct one in part D. The minimum SE means that this regression line, shown for box \#2 in part C, is a better statistical estimate of the density than afforded by measurement boxes that are larger with more points (but contain an excess of empty space) or smaller with fewer points. 

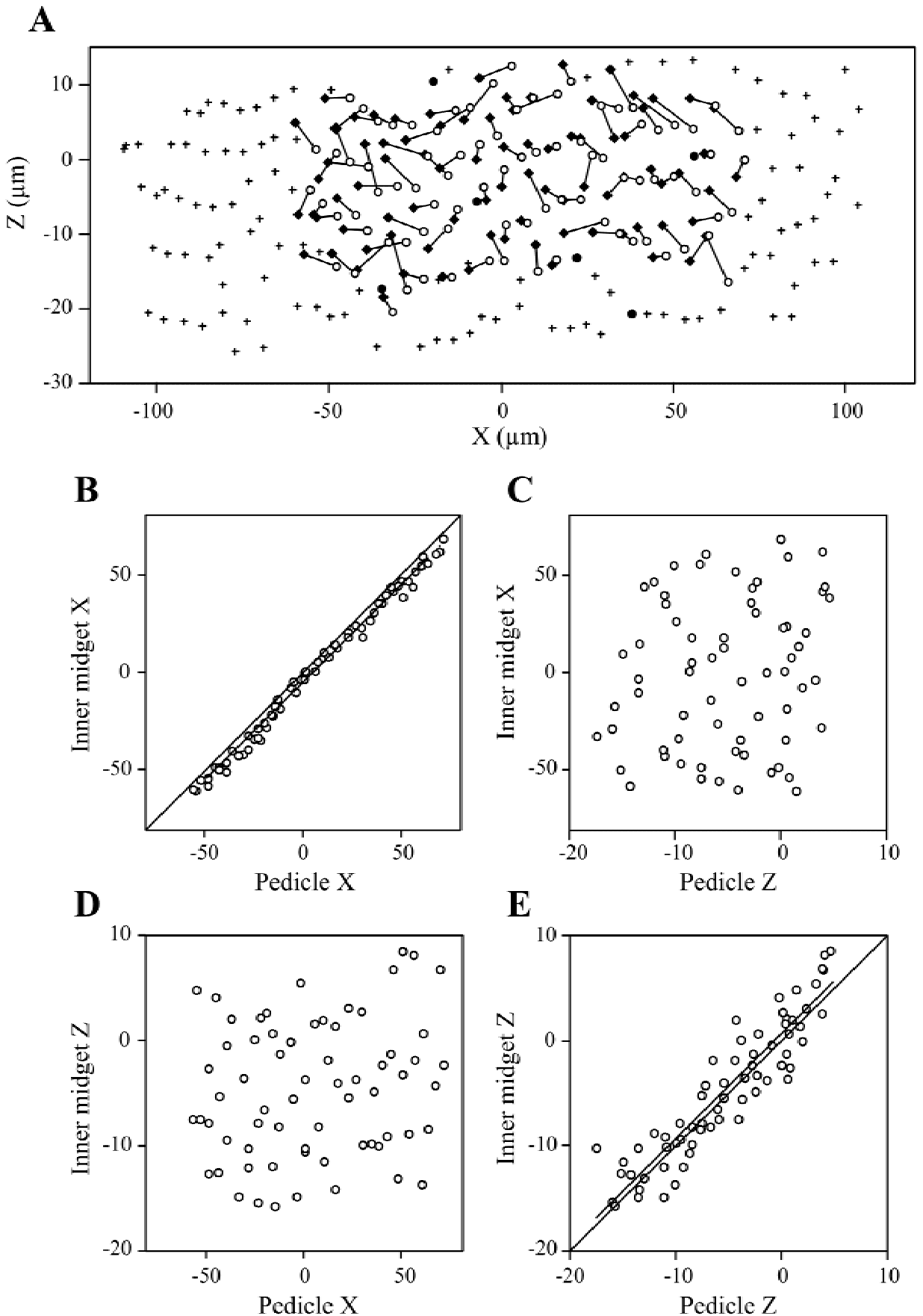

Fig. 5. Lateral displacement and magnification from cone pedicles to inner midget bipolar somas. A: A line segment connects the location of each L or M cone pedicle (open circle) to its inner midget bipolar cell soma (filled diamond), which is slightly displaced in the direction away from the fovea. S-cone pedicles (filled circles) do not contact inner midget bipolar cells. Plus symbols represent pedicles whose inner midget bipolar cells have not been identified. B-E: Calculation of areal magnification from pedicles to inner midget bipolar cells requires four measurements, illustrated in parts B-D. B: Dependence of the $X$ coordinates of inner midget bipolar cells on the $X$ coordinates of their pedicles. C: Dependence of the $X$ coordinates of inner midget bipolar cells on the $Z$ coordinates of their pedicles. D: Dependence of the $Z$ coordinates of inner midget bipolar cells on the $X$ coordinates of their pedicles. E: Dependence of the $Z$ coordinates of inner midget bipolar cells on the $Z$ coordinates of their pedicles. Long lines in parts $\mathrm{B}$ and $\mathrm{E}$ have unity slope and zero intercept. Shorter lines in B and $\mathrm{E}$ are best-fitting lines to the points.

(constant) displacement of outer midget bipolar cells was $13.0 \mu \mathrm{m}-$ more than the $5.3 \mu \mathrm{m}$ of inner midget bipolar cells-as a result of the deeper position of outer midget bipolar cells within the INL.
The lateral displacement from cone pedicles to GCL cells was much greater, increasing from $50 \mu \mathrm{m}$ for pedicles at $480 \mu \mathrm{m}$ from the fovea to $65 \mu \mathrm{m}$ for pedicles at $580 \mu \mathrm{m}$. Radial magnification was therefore 1.15 , calculated from a span of $100 \mu \mathrm{m}(580 \mu \mathrm{m}-$ 
$480 \mu \mathrm{m}=)$ in the pedicle layer to a span of $115 \mu \mathrm{m}(=645 \mu \mathrm{m}-$ $530 \mu \mathrm{m}$ ) in the GCL. The group of pedicles centered at $530 \mu \mathrm{m}-$ midway between $480 \mu \mathrm{m}$ and $580 \mu \mathrm{m}$-therefore connected to a group of GCL cells centered at $587 \mu \mathrm{m}$-midway between $645 \mu \mathrm{m}$ and $530 \mu \mathrm{m}$-giving a circumferential magnification of 1.11 $(=587 / 530)$. Areal magnification, the product of these linear magnifications, was 1.27. Therefore, GCL cell and pedicle densities were compared for the region of GCL cells centered at $587 \mu \mathrm{m}$ and the region of pedicles centered at $530 \mu \mathrm{m}$. The GCL cell density was multiplied by $95 \%$ to discount the $5 \%$ of CGL cells that were displaced amacrine cells in central retina (Wässle et al., 1990). Finally, the ganglion cell density (ganglion cells $\mathrm{mm}^{-2}$ in the GCL) was multiplied by 1.27 in order to compute ganglion cell density corresponding to $1 \mathrm{~mm}^{2}$ at the level of the pedicles.

\section{Results}

\section{Identification of bipolar cells}

We tracked the dendrites of 229 bipolar cells to their contacts with photoreceptor terminals. Based on the number and type of photoreceptor terminals contacted, we identified the bipolar cells as midget, diffuse, inner S-cone, or rod bipolar (Table 2).

We classified all midget and many diffuse bipolar cells as inner or outer by two methods. The first method depended on the location of bipolar terminals in the IPL: outer terminals in the outer ( $a$ or OFF) half of the IPL and inner terminals in the inner ( $b$ or
ON) half (Famiglietti \& Kolb, 1976; Nelson et al., 1978; Boycott \& Hopkins, 1993). Within each half, there was further sublamination. For example, inner S-cone and rod bipolar cells terminated in the innermost part of the inner half (Fig. 2). Inner midget bipolar cells terminated at a level slightly outward of those, and inner diffuse bipolar cells terminated even more outward within the inner half.

The second method depended on the nature of the contacts with cone pedicles in the OPL. Inner midget bipolar cell and inner $S$-cone bipolar cell dendrites invaginated their cone pedicles and provided the central elements of triads. The specialized membrane densities at these contacts were asymmetric, with a thicker presynaptic (pedicle) membrane density and a less thick postsynaptic (bipolar dendrite) membrane density (Fig. 6; Vardi et al., 1998). Inner diffuse bipolar cells made both invaginating and basal contacts with their cone pedicles (Hopkins \& Boycott, 1995, 1996, 1997; Calkins et al., 1996). Of particular importance, all of these invaginating and basal contacts also involved asymmetric membrane densities (Fig. 6), where the mGluR6 type of glutamate receptor has been localized (Vardi et al., 2000). Dendrites of the rod bipolar cells, which are $\mathrm{ON}$, invaginated rod spherules, where the membrane densities were also asymmetric. Some rod bipolar dendrites also failed to reach a spherule.

By contrast, outer midget bipolar cell dendrites made exclusively flat or basal contacts with their cone pedicles (Kolb et al., 1969). These contact regions exhibited symmetrically dense membranes (Fig. 6; Vardi et al., 1998). Similarly, outer diffuse bipolar

Table 2. Identification of inner and outer bipolar cells ${ }^{\mathrm{a}}$

\begin{tabular}{|c|c|c|c|c|c|c|c|}
\hline \multirow[b]{2}{*}{ Cell group } & \multirow[b]{2}{*}{ Number } & \multicolumn{2}{|c|}{ IPL sublayer } & \multirow{2}{*}{$\begin{array}{c}\text { OPL } \\
\text { symmetric } \\
\& \text { basal }\end{array}$} & \multirow{2}{*}{$\begin{array}{c}\text { OPL } \\
\text { asymmetric/ } \\
\text { invaginating }\end{array}$} & \multirow[b]{2}{*}{ Pale } & \multirow[b]{2}{*}{ Dense } \\
\hline & & $a$ & $b$ & & & & \\
\hline \multicolumn{8}{|l|}{ Inner bipolar cells } \\
\hline \multirow{2}{*}{ Midget (86) } & 28 & & + & & + & & + \\
\hline & 58 & & & & + & & + \\
\hline \multirow{4}{*}{ Diffuse (43) } & 4 & & + & & + & & + \\
\hline & 11 & & + & & & & + \\
\hline & 9 & & & & + & & + \\
\hline & 19 & & & & & & + \\
\hline \multirow[t]{2}{*}{ Inner $S$ cone $(12)$} & 3 & & + & & + & & + \\
\hline & 9 & & & & + & & + \\
\hline Rod (4) & 4 & & + & & + & + & \\
\hline \multicolumn{8}{|l|}{ Outer bipolar cells } \\
\hline \multirow[t]{2}{*}{ Midget (91) } & 32 & + & & + & & + & \\
\hline & 59 & & & + & & + & \\
\hline \multirow[t]{4}{*}{ Diffuse (77) } & 16 & + & & + & & + & \\
\hline & 16 & + & & & & + & \\
\hline & 7 & & & + & & + & \\
\hline & 38 & & & & & + & \\
\hline
\end{tabular}

${ }^{a}$ Six groups of bipolar cell are identified. The total number of each group is shown in parentheses. Some cells were tracked to their terminals in the outer ( $a$ or OFF) half or the inner ( $b$ or ON) half of the inner plexiform layer (IPL), which identified them as outer or inner. Midget bipolar cells in the fovea receive all or almost all of their contacts from one cone. Diffuse bipolar cells in the fovea are contacted by several (6-12) contiguous cones. Inner S-cone bipolar cells are contacted by several widely spaced cones. Both inner midget and inner S-cone bipolar cells invaginate the pedicle and provide central elements for triads. Their contacts show asymmetrically dense membranes, which are denser on the cone pedicle side than on the bipolar side. All of the contacts onto inner diffuse bipolar cells are similarly asymmetrically dense, but only some of the contacts are invaginating. Dendrites of rod bipolar cells invaginate rod spherules and also make asymmetric densities or fail to reach a spherule. Outer midget bipolar cells make exclusively basal contacts in the OPL with their pedicles. Their basal contacts have symmetric membrane densities, equally dense on the pedicle and bipolar side. All of the contacts made by cone pedicles onto outer diffuse bipolar cells are also basal and symmetrically dense. Pale versus Dense refers to the appearance of a cell soma, its dendritic processes, and its synaptic terminal, as is illustrated in Figs. 1 and 2. 

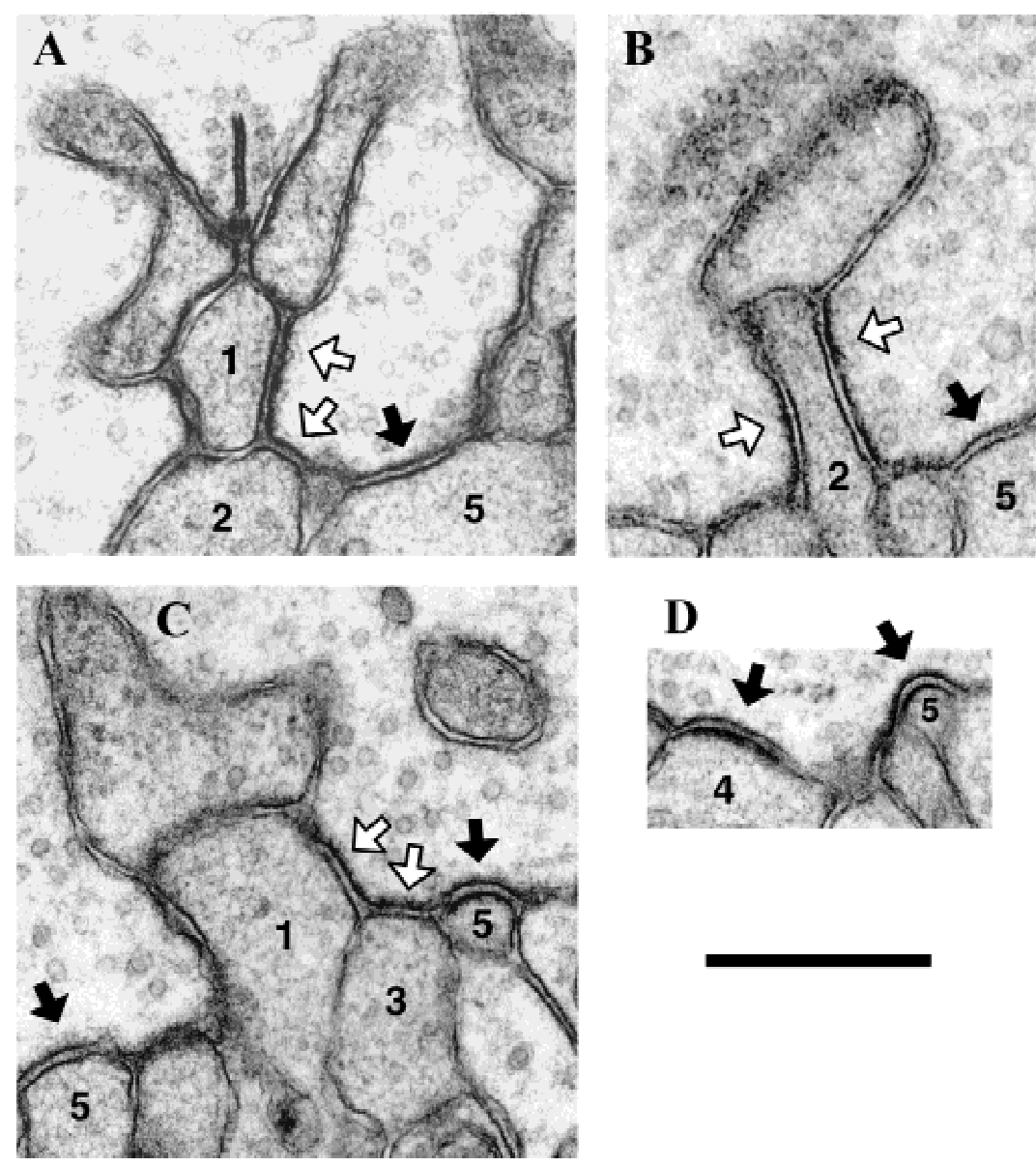

Fig. 6. Membrane densities at contacts between cone pedicles and bipolar cells (A-D). Bipolar processes are numbered according to bipolar cell type and whether they are invaginating, that is, a central element within a triad, or basal: (1) central elements of inner midget bipolar cells; (2) central elements of inner diffuse bipolar cells; (3) basal contacts of inner diffuse bipolar cells; (4) basal contacts of outer midget bipolar cells; and (5) basal contacts of outer diffuse bipolar cells. Identifications of cell type (inner/outer and midget/ diffuse) are described in the legend for Table 2. White arrows indicate asymmetric contacts with a denser presynaptic (pedicle) cell membrane and a less dense postsynaptic (bipolar) cell membrane. Black arrows point to symmetric contacts with equally dense presynaptic and postsynaptic membranes. The pedicle makes asymmetric contacts onto inner midget, inner diffuse, and inner S-cone bipolar cells and symmetric contacts onto outer midget and outer diffuse bipolar cells. Vardi et al. (1998) make the same distinction. Correspondingly, Raviola and Gilula (1975) report two kinds of contact, one made by the pedicle onto central elements, showing presynaptic "fluff", the other made by the pedicle onto (some) basal processes, without presynaptic fluff. As illustrated by the unlabeled contacts, the distinction between symmetric and asymmetric contacts cannot be made unless the plane of section is very close to a perfect cross section. Scale bar $=0.5 \mu \mathrm{m}$. cells made only basal contacts (Hopkins \& Boycott, 1995, 1996, 1997), and all of these were symmetrically dense as well (Fig. 6; Vardi et al., 1998).

We classified all midget bipolar cells by one or both methods (Table 2). We classified many non-midget bipolar cells either by the OPL method (symbols with filled upper halves in Fig. 7), the IPL method (symbols with filled lower halves in Fig. 7), or both methods (completely filled symbols). We found agreement between the OPL and IPL methods in all cases where we could apply both methods (Table 2).

At an early stage of this effort, we noticed that some cellsdendrites and terminal as well as soma-were more electron dense, whereas others were less electron dense. These dense and pale somas are evident in Fig. 1A and are identified as "+" (dense) and "-" (pale) in the overlay in Fig. 1B. Dense and pale bipolar somas in electron photomicrographs were previously reported (Missotten, 1974; Martin \& Grünert, 1992). Cells with dense somas have dense terminals, and cells with pale somas have pale terminals, as shown in Fig. 2A and identified as "+" and "-" in the overlay in Fig. 2B.

For every one of the 177 midget bipolar cells (91 inner and 86 outer) and 63 diffuse bipolar cells (24 inner and 39 outer) that we could identify as inner or outer by either or both of the OPL and IPL methods, and for 12 inner S-cone bipolar cells, we found that "dense" is equal to "inner" and "pale" is equal to "outer" (Table 2). Rod bipolar cells, an ON type of cell, were pale and constituted the only exception to this rule. These findings appear to correspond perfectly to the distinction made from electron photomicrographs by Koontz and Hendrickson (1987) between bipolar cells with "granular" cytoplasm and those with "agranular" cytoplasm: Their foveal granular cells terminated in the inner half of the IPL; their foveal agranular cells terminated in the outer half, but somepresumably rod bipolar cells-terminated in the innermost IPL.

Since the rod bipolar cells broke the "Dense $=$ inner, Pale $=$ outer" rule, we were concerned about the possibility that one or more of the estimated six types of diffuse bipolar cells (Boycott \& Wässle, 1991) might also break the rule. By saturating the region in the box in Fig. 7, we were able to rule out that possibility. We identified every non-midget outer bipolar cell within the box in Fig. 7A and every (but two) non-midget inner bipolar cell within the same box in Fig. 7B by either or both of the standard methods. We found no exceptions to the "Dense $=$ inner, Pale $=$ outer rule" among the 19 so identified inner diffuse bipolar cells, five inner S-cone bipolar, and 34 outer diffuse bipolar cells in the nearly saturated region defined by the box. (We did not have complete saturation, as we were unable to identify two of the 21 diffuse bipolar cells-presumed to be inner-in the box by either of the standard methods.) We therefore had a third method for discriminating inner from outer cells, a method that we were able to apply to those diffuse bipolar cell somas whose terminals were not in our series of sections and whose OPL contacts we did not or could not scrutinize. Based on all three methods, we found similar numbers of inner midget, outer midget, and outer diffuse bipolar cells, but substantially fewer inner diffuse bipolar cells (Table 2). These counts anticipate results of cell densities that we present below. 

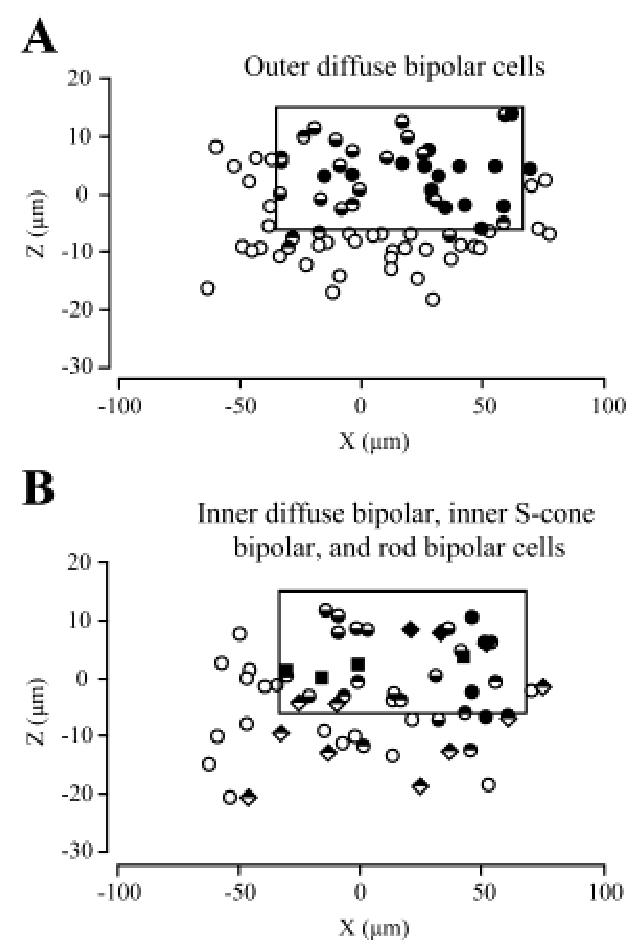

Fig. 7. Two standard methods for classification of non-midget bipolar cells as outer (A) or inner (B) confirm a third method based on pale or dense appearance of cells. Diffuse bipolar cells are represented by circles, inner S-cone bipolar cells by diamonds, and rod bipolar cells by squares. A symbol whose bottom half is filled marks the location of the main dendrite of a cell that has been classified by the location of its terminals in the $a$ (outer) or $b$ (inner) half of the IPL. A symbol whose top half is filled marks a cell that has been classified by the nature of its dendritic contacts with cone pedicles in the OPL, asymmetric and sometimes invaginating (inner) versus symmetric and never invaginating (outer). A completely filled symbol marks a cell that has been classified by both IPL and OPL methods. All but two of the 34 diffuse bipolar cells in the box in part A have been affirmatively classified by one or both standard methods, and all are pale. All of the 21 inner diffuse bipolar cells and five inner S-cone bipolar cells in the (same) box in part B have been affirmatively identified, and all are dense. All of the four rod bipolar cells in the box in part B have been affirmatively identified, and all are pale. Outside the box, many cells (open symbols) have been classified as inner or outer only by virtue of their dense or pale appearance.

Equality of computed densities of midget bipolar cells and cone pedicles serves as a control

Dating from Polyak's (1941) discovery of midget bipolar cells and the discovery of invaginating (inner) and flat (outer) midget bipolar cells (Kolb et al., 1969; Kolb, 1970), it is generally assumed that there is one of each kind of midget bipolar cell for each foveal cone. By reconstruction and tracking of 86 inner midget bipolar cells and 91 outer midget bipolar cells, we found that this assumption was not quite correct, that there was an important exception. Specifically, there were no inner midget bipolar cells for $\mathrm{S}$ cones, as first suggested in an abstract by Klug et al. (1991). There were, however, in the foveal patch we studied, one outer midget bipolar cell for each of $91 \mathrm{~L}, \mathrm{M}$, and S cones, and with one exception, one inner midget bipolar cell for each of $87 \mathrm{~L}$ and $\mathrm{M}$ cones. (The exception was one inner midget bipolar cell that was "doubleheaded" and served two cones (Polyak, 1941; Boycott \& Hopkins,
1991; Hopkins \& Boycott, 1992).) Outer midget bipolar cells contacted by $\mathrm{S}$ cones resembled those contacted by other cones at both OPL and IPL levels (Klug et al., 1992). Therefore, we were able to use these one-for-one relationships that we demonstrated in our material as a control to validate our method for measuring and comparing cell densities.

The arrays of cone pedicles in Fig. 8 are larger than the arrays of outer and inner midget bipolar cells, as explained in the legend. The density of all pedicles was 26,512 pedicles $\mathrm{mm}^{-2}$. The array of outer midget bipolar cells (Fig. 8) should have had the same density and did: our method gave 26,117 cells $\mathrm{mm}^{-2}$, which gave a density ratio of outer midget bipolar cells to cone pedicles of 0.99 , just $1 \%$ less than unity (Table 3 ). Similarly, the density of inner midget bipolar cells (Fig. 8), after adding one cell to compensate for the double-headed inner midget bipolar cell, is the same as the density of L/M-cone pedicles. These controls confirmed the use of the expanding box method for determining the measurement box and the use regression to compute cell density.

With the optimal measurement box determined as above, we also computed cell density simply by dividing the number of points by the area. Cell density ratios based on these values generally matched those computed by regression (Table 3 ). However, in a critical control, the ratio of the simple density of outer midget bipolar cells to that of cones was 0.95 instead of unity, confirming that simple cell densities are less reliable than those computed by regression.

\section{Comparison of the densities of INL cells and cone pedicles}

The arrays of horizontal cell somas, the OPL trunks of Müller cells, Müller cell somas, and INL amacrine cell somas, are shown in Fig. 9. This figure also shows the measurement boxes and best-fitting lines from which we obtained their spatial densities, as described in Materials and methods. Horizontal cell density was clearly less $(83 \%)$ than the density of cone pedicles (Fig. 9 \& Table 3). From this same material, Burris et al. (2002) reported that the density of OPL trunks of Müller cells was equal to that of cone pedicles, and using slightly different methods, we confirmed that conclusion for OPL trunks $\left(26,661 \mathrm{~mm}^{-2}\right)$. The density of INL amacrine cell somas $\left(26,784 \mathrm{~mm}^{-2}\right)$ was only $1 \%$ greater than the density of cone pedicles.

The arrays of the main dendrites of outer diffuse bipolar cells, inner diffuse bipolar cells, and All bipolar cells are shown in Fig. 10. The density of outer diffuse bipolar cells, 23,327 cells $\mathrm{mm}^{-2}$, was only slightly smaller ( $88 \%$ ) than the density of cone pedicles. However, 38 of the 77 "outer diffuse" bipolar cells were identified solely on the basis of their pale appearance (Table 2), and some of these might have been rod bipolar cells, which are also pale. We estimate that these unidentified rod bipolar cells could have been $9 \%$ of the 38. (We obtained this estimate by dividing 4, the number of identified rod bipolar cells, by 43 , the number of pale cells identified by standard methods, the sum of 39 outer diffuse bipolar cells so identified and the four rod bipolar cells.) Therefore, of those 38 pale cells, we suppose that three might have been rod bipolar cells instead of outer diffuse bipolar cells, potentially reducing the total count of outer diffuse bipolar cells to 74 , their density by at most $5 \%$, and their density compared to cones to $84 \%$.

By contrast, the density of inner diffuse bipolar cells, 10,514 cells $\mathrm{mm}^{-2}$, was much smaller, just $40 \%$ of the density of cone pedicles. This large difference between the densities of outer and 

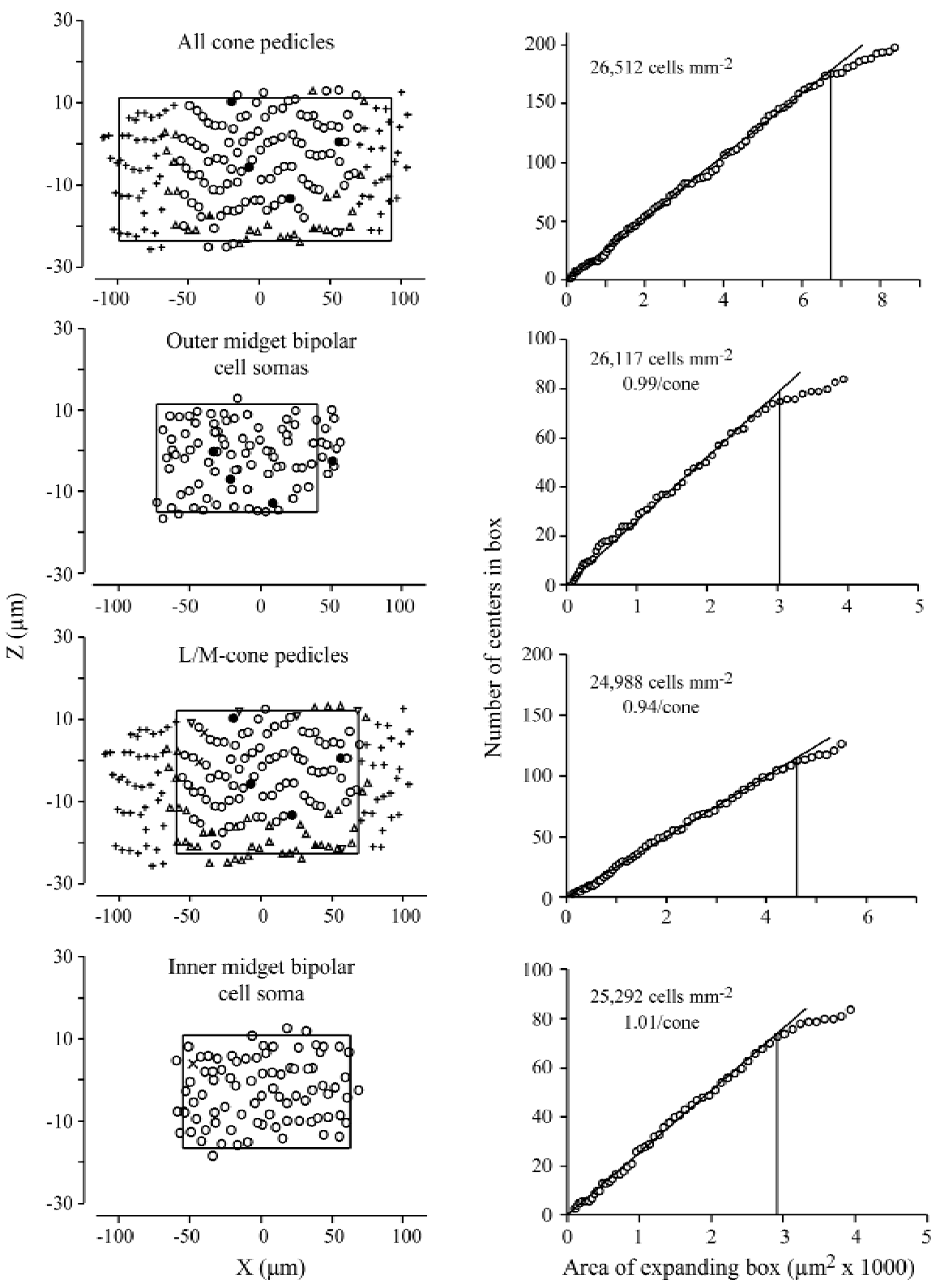

Fig. 8. Densities of cone pedicles and midget bipolar cells. These data permit comparison of densities of All cone pedicles with outer midget bipolar cell somas and comparison of densities of L/M-cone pedicles with inner midget bipolar cells (after compensation for one double-headed inner midget bipolar cell). After rotations of center coordinates as described in Fig. 3, the density of each array of retinal cells within its measurement box (cf. Fig. 4) (left) is computed by the expanding box method (right). The vertical lines on the right mark areas of measurement boxes. We locate bipolar cells over a smaller region than cone pedicles because we require complete reconstruction of bipolar dendrites, which is limited to the region photographed at $2000 \times$, by the more lateral location of bipolar cells than their pedicles, and by a slight tilt of the plane of section. All cone pedicles. Open symbols represent L or M cone pedicles; the (six) filled symbols represent S-cone pedicles. Each circle represents a pedicle whose outer midget bipolar cell soma was identified. We measure the density of all of the cone pedicles in our series, even those whose outer midget bipolar cells have no soma in the $2000 \times$ series of photomicrographs (triangles). Some of these pedicles are marked by upward-pointing triangles because their midget bipolar cells have a main dendrite within the series. Some others are marked by downward-pointing triangles because they do not have midget bipolar main dendrites within the series. Plus symbols indicate those pedicles that have not been classified as S versus $\mathrm{M}$ or $\mathrm{L}$. Outer midget bipolar cell somas. Corresponding to the above, open circles mark centers of outer midget bipolar cell somas that are contacted by an L or M cone. Filled circles mark centers of outer midget bipolar cell somas that are contacted by an S cone. (Two outer midget bipolar cells contacted by S cones are absent because their cell somas are not in the series.) L/M-cone pedicles. S-cone pedicles ( filled symbols) do not contact inner midget bipolar cells; therefore, we compare the densities of inner midget bipolar cells with L/M-cone pedicles (open symbols). This density measurement includes L/M-cone pedicles whose inner midget bipolar cell somas are identifiable (open circles) and those whose inner midget bipolar cell somas are not in the $2000 \times$ series (open triangles). Some of the latter have a midget bipolar main dendrite (upward-pointing triangles), and some have dendritic branches but no midget bipolar main dendrite (downward-pointing triangles). Because $\mathrm{S}$ cones do not have inner midget bipolar cells, the density measurement area excludes regions in which pedicles are not classified as $\mathrm{S}$ versus $\mathrm{M}$ or $\mathrm{L}$ (plus symbols). Two of the pedicles, represented by " $\chi$ ”, share a single (double-headed) inner midget bipolar cell. Inner midget bipolar cell somas. Corresponding to the above, open circles mark inner midget bipolar cell somas that are contacted by an $\mathrm{L}$ or an $\mathrm{M}$ cone. The " $\chi$ " marks the double-headed inner midget bipolar cell. The density measurement includes two inner midget bipolar cells at this position in order to serve the purposes of this control, which requires one inner midget bipolar cell soma for each L/M-cone pedicle. 
Table 3. Spatial density of cells in macaque fovea [Densities (slopes) are obtained from best-fitting lines through the origin, as described in Materials and methods and Fig. 4]

\begin{tabular}{|c|c|c|c|c|c|c|c|c|}
\hline \multicolumn{2}{|l|}{ Cell type } & $\begin{array}{c}\text { Density } \\
\left(\text { cells } \mathrm{mm}^{-2} \text { ) }\right.\end{array}$ & $\begin{array}{l}\text { Ratio to } \\
\text { cones }^{\mathrm{a}}\end{array}$ & $\begin{array}{c}\text { Sum } \\
\text { Fit }\end{array}$ & $\begin{array}{c}\text { Simple } \\
\text { density } \\
\text { (cells } \mathrm{mm}^{-2} \text { ) }\end{array}$ & $\begin{array}{l}\text { Standard } \\
\text { error }\end{array}$ & $\begin{array}{c}\text { Coefficient } \\
\text { of variation } \\
(\%)\end{array}$ & $\begin{array}{l}\text { Simple } \\
\text { ratio to } \\
\text { cones }\end{array}$ \\
\hline \multicolumn{9}{|c|}{ Photoreceptor terminals } \\
\hline \multirow{2}{*}{\multicolumn{2}{|c|}{$\begin{array}{l}\text { All cone pedicles } \\
\mathrm{L} / \mathrm{M} \text { cone pedicles }\end{array}$}} & 26,512 & & & 26,162 & 1610 & 6.2 & \\
\hline & & 24,988 & 0.94 & & 24,675 & 2239 & 9.1 & 0.94 \\
\hline \multicolumn{2}{|c|}{$\mathrm{S}$ cone pedicles (subtracted) ${ }^{\mathrm{b}}$} & 1524 & 0.06 & & & & & \\
\hline \multicolumn{2}{|c|}{$\mathrm{S}$ cone pedicles } & 1452 & 0.05 & & & & & \\
\hline \multicolumn{2}{|c|}{ Rod spherules ${ }^{c}$} & 1501 & & & & & & \\
\hline \multicolumn{2}{|c|}{ Horizontal cell somas } & 21,885 & 0.83 & & 21,049 & 2937 & 14.0 & 0.80 \\
\hline \multicolumn{2}{|c|}{ Müller cell OPL trunks ${ }^{\mathrm{d}}$} & 26,661 & 1.01 & & 25,721 & 3588 & 14.0 & 0.98 \\
\hline \multicolumn{2}{|c|}{ Müller cell somas } & 25,749 & 0.97 & & 24,614 & 2771 & 11.3 & 0.94 \\
\hline \multicolumn{9}{|c|}{ Bipolar cells } \\
\hline & 26,117 & 0.99 & & 24,755 & 3942 & 15.9 & 0.95 \\
\hline \multirow{2}{*}{\multicolumn{2}{|c|}{$\begin{array}{ll}+\mathrm{M} & \text { Inner midget bipolar cell somas } \\
+\mathrm{M} & \text { Inner midget bipolar cell somas }+1^{\mathrm{f}}\end{array}$}} & 25,181 & $1.01^{\mathrm{e}}$ & & 24,675 & 2239 & 9.1 & 1.00 \\
\hline & & 25,292 & $1.01^{\mathrm{e}}$ & & & & & \\
\hline \multirow{2}{*}{\multicolumn{2}{|c|}{$\begin{array}{ll}\text {-D } & \text { Outer diffuse bipolar cell main dendrites } \\
+\mathrm{D} & \text { Inner diffuse bipolar cell main dendrites }\end{array}$}} & 23,327 & 0.88 & & 21,684 & 3990 & 18.4 & 0.83 \\
\hline & & 10,514 & 0.40 & & 9510 & 1463 & 15.4 & 0.36 \\
\hline \multirow{3}{*}{$\begin{array}{l}+\mathrm{S} \\
+\mathrm{S}+\mathrm{R} \\
+\mathrm{R}\end{array}$} & Inner $\mathrm{S}$ cone bipolar cell main dendrites & 2702 & $1.86^{\mathrm{g}}$ & & 213 & 657 & 27.2 & \\
\hline & Rod and inner $\mathrm{S}$ cone bipolar cell main dendrites & 4428 & & & 3828 & 781 & 20.4 & \\
\hline & Rod bipolar cell main dendrites ${ }^{\mathrm{h}}$ & 1726 & & & & & & \\
\hline & Inner and outer midget bipolar cell somas & 51,278 & 1.93 & & 50,167 & 6198 & 12.4 & 1.92 \\
\hline & Inner and outer midget bipolar cell somas $(\mathrm{sum})^{\mathrm{i}}$ & 51,298 & 1.93 & 1.00 & & & & \\
\hline & Inner and outer diffuse bipolar cell main dendrites & 34,838 & 1.31 & & 34,194 & 2408 & 7.0 & 1.31 \\
\hline & Inner and outer diffuse bipolar cell main dendrites (sum) $)^{\mathrm{i}}$ & 33,841 & 1.28 & 0.97 & & & & \\
\hline & All bipolar cells & 91,714 & 3.46 & & 90,370 & 5218 & 5.8 & 3.45 \\
\hline & All bipolar cells $(\text { sum })^{\mathrm{k}}$ & 89,567 & 3.38 & 0.98 & & & & \\
\hline INL Amac & rine cell somas & 26,784 & 1.01 & & 25,334 & 3959 & 15.6 & 0.97 \\
\hline GCL cells & & 53,798 & & & 51,709 & 6830 & 13.2 & \\
\hline Ganglion & ells ${ }^{\mathrm{j}}$ & 64,907 & 2.45 & & & & & \\
\hline
\end{tabular}

${ }^{a}$ The Ratio to cones is the ratio of the density of a cell type to the density of All cone pedicles unless otherwise specified.

${ }^{\mathrm{b}}$ This density is calculated by subtracting the density of $L / M$-cone pedicles from the density of All cone pedicles.

${ }^{\mathrm{c}}$ The density of Rod spherules is not uniform over the area we examined. The foveal side is empty of rod spherules, whereas the peripheral side has the density shown.

${ }^{\mathrm{d}}$ Each Müller cell has one OPL trunk at the level of the cone pedicles (Burris et al., 2002).

${ }^{\mathrm{e}}$ Since $\mathrm{S}$ cones do not contact inner midget bipolar cells, the density of inner midget bipolar cell somas $(+\mathrm{M})$ is compared to that of $L / M$-cone pedicles. ${ }^{\mathrm{f}}$ For use as a control, the one double-headed inner midget bipolar cell is counted as two cells so that its two cone pedicles would have one inner midget bipolar cell each.

${ }^{\mathrm{g}}$ The density of inner $S$-cone bipolar cell main dendrites $(+\mathrm{S})$ is compared to the density of $S$-cone pedicles.

${ }^{\mathrm{h}}$ Because rod bipolar cells are too few in number to compute their density with the expanding box method, the density of Rod bipolar cell main dendrites $(+\mathrm{R})$ is calculated by subtracting the density of inner S-cone bipolar cell main dendrites $(+\mathrm{S})$ from the density of the combined arrays of Rod bipolar and inner S-cone bipolar cell main dendrites $(+\mathrm{S}+\mathrm{R})$.

${ }^{\mathrm{i}}$ This value is calculated by summing the inner bipolar cell density and the outer bipolar cell density.

${ }^{\mathrm{j}}$ This density is calculated by summing the densities of outer midget bipolar cell somas $(-\mathrm{M})$, inner midget bipolar cell somas $(+\mathrm{M})$, outer diffuse bipolar cell main dendrites $(-\mathrm{D})$, inner diffuse bipolar cell main dendrites $(+\mathrm{D})$, and the combined Rod and inner S-cone bipolar cell main dendrites $(+\mathrm{S}+\mathrm{R})$. ${ }^{\mathrm{k}}$ Ganglion cell density is corrected for areal magnification (1.27) and for displaced amacrine cells $(5 \%)$. The ratio is compared with the pedicle density of the corresponding area (see Methods), 24,754 pedicles $\mathrm{mm}^{-2}$.

inner diffuse bipolar cells is easy to see in raw counts in Table 2 and in Figs. 1 and 2. Specifically, Table 2 shows that we identified 77 outer and just 43 inner diffuse bipolar cells in our material. [By comparison, we identified nearly identical numbers of outer midget bipolar cells, 91, and inner midget bipolar cells, 86. Even this small difference was for a reason: $\mathrm{S}$ cones do not have an inner midget bipolar cell (Herr et al., 2003).] In addition, the photomicrograph shown in Fig. 1 has 21 outer (-D) but only 12 inner (+D) diffuse bipolar cell somas in the INL. [By comparison, the same photomicrograph has 22 outer $(-\mathbf{M})$ and 18 inner $(+\mathbf{M})$ midget bipolar cell somas.] Finally, the photomicrograph shown in
Fig. 2 has five outer ( $-\mathbf{D})$ but only two inner (+D) diffuse bipolar cell terminals in the IPL. [This region has equal numbers, seven outer $(-\mathbf{M})$ and seven inner $(+\mathbf{M})$, midget bipolar cell terminals.] These examples were also consistent with the finding that outer diffuse bipolar cell density was comparable to midget bipolar cell and cone pedicle densities.

As another check of our density measurement method, we calculated the densities for arrays (not shown) that combined inner and outer midget bipolar cells $\left(51,278\right.$ cells $\left.\mathrm{mm}^{-2}\right)$, inner and outer diffuse bipolar cells $\left(34,838\right.$ cells $\left.\mathrm{mm}^{-2}\right)$, and all bipolar cells $\left(91,714\right.$ cells $\left.\mathrm{mm}^{-2}\right)$, and we found values close to the sums 

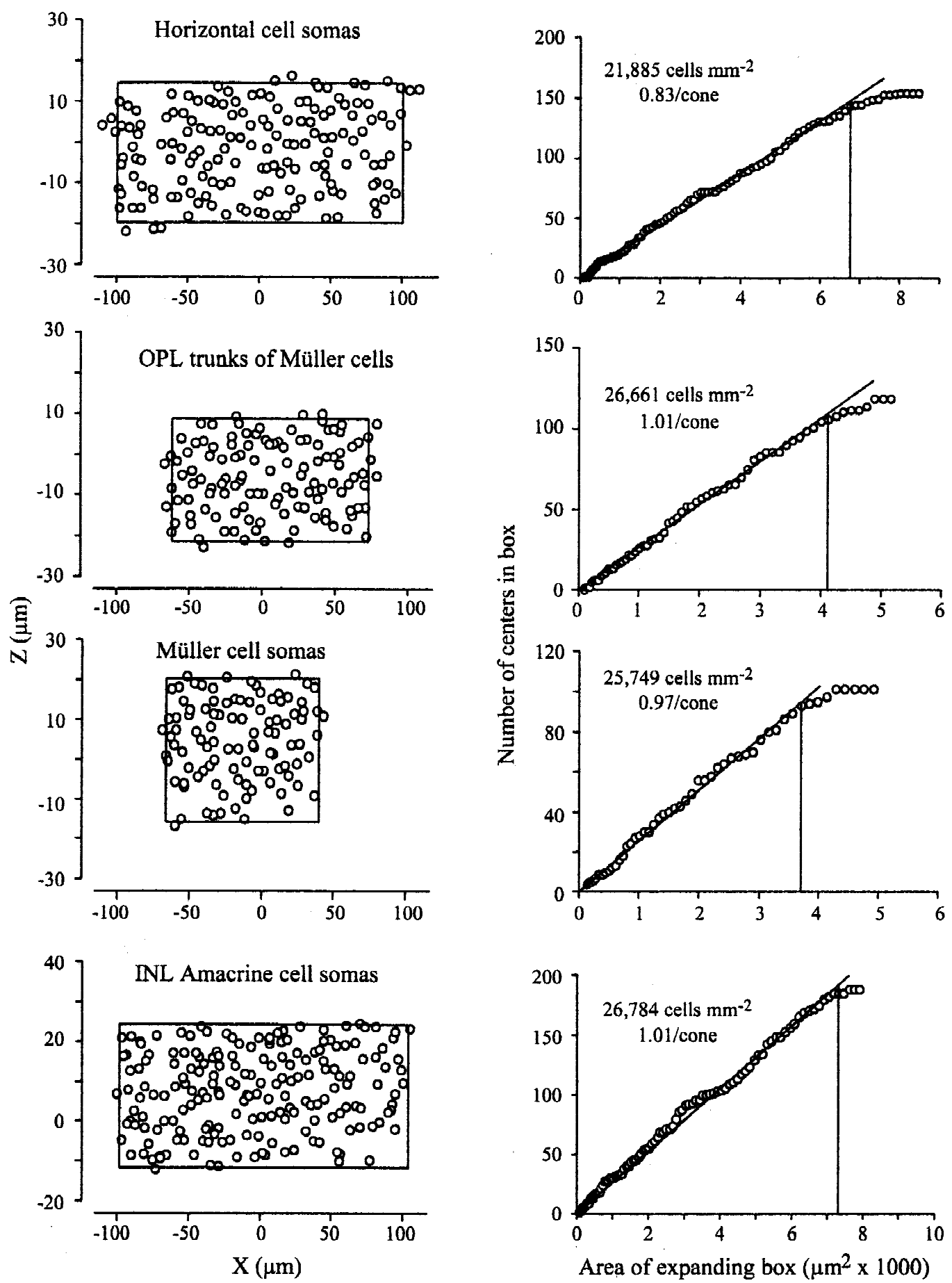

Fig. 9. Densities of horizontal cell somas, OPL trunks of Müller cells, Müller cell somas, and amacrine cell somas that reside in the INL. Identification of these cells is described in Materials and methods. After rotations of center coordinates as described in Fig. 3, the density of each array of retinal cells within its measurement box (cf. Fig. 4) (left) is computed by the expanding box method (right). The vertical lines on the right mark areas of measurement boxes.

of the densities of each group alone $(51,298,33,841$, and 89,567 cells $\mathrm{mm}^{-2}$ ) (Table 3).

There were only six S-cone pedicles in our material, so their density measurement might not have been accurate. We directly measured their density (1452 pedicles $\mathrm{mm}^{-2}$ ) in the (by now) usual way. The density (1524 pedicles $\mathrm{mm}^{-2}$ ) obtained by subtracting the density of $\mathrm{L} / \mathrm{M}$ cones from the density of All cones was essentially the same (Table 3 ). Our material had only 12 inner S-cone bipolar cells, so their density, 2702 cells $\mathrm{mm}^{-2}$, might not have been perfectly accurate as well. As shown by Herr et al. (2003) for this patch of retina, in agreement with findings of Kouyama and Marshak (1997), there are $\sim 2$ inner S-cone bipolar cells for each $\mathrm{S}$ cone. Our density values were compatible with that finding. 

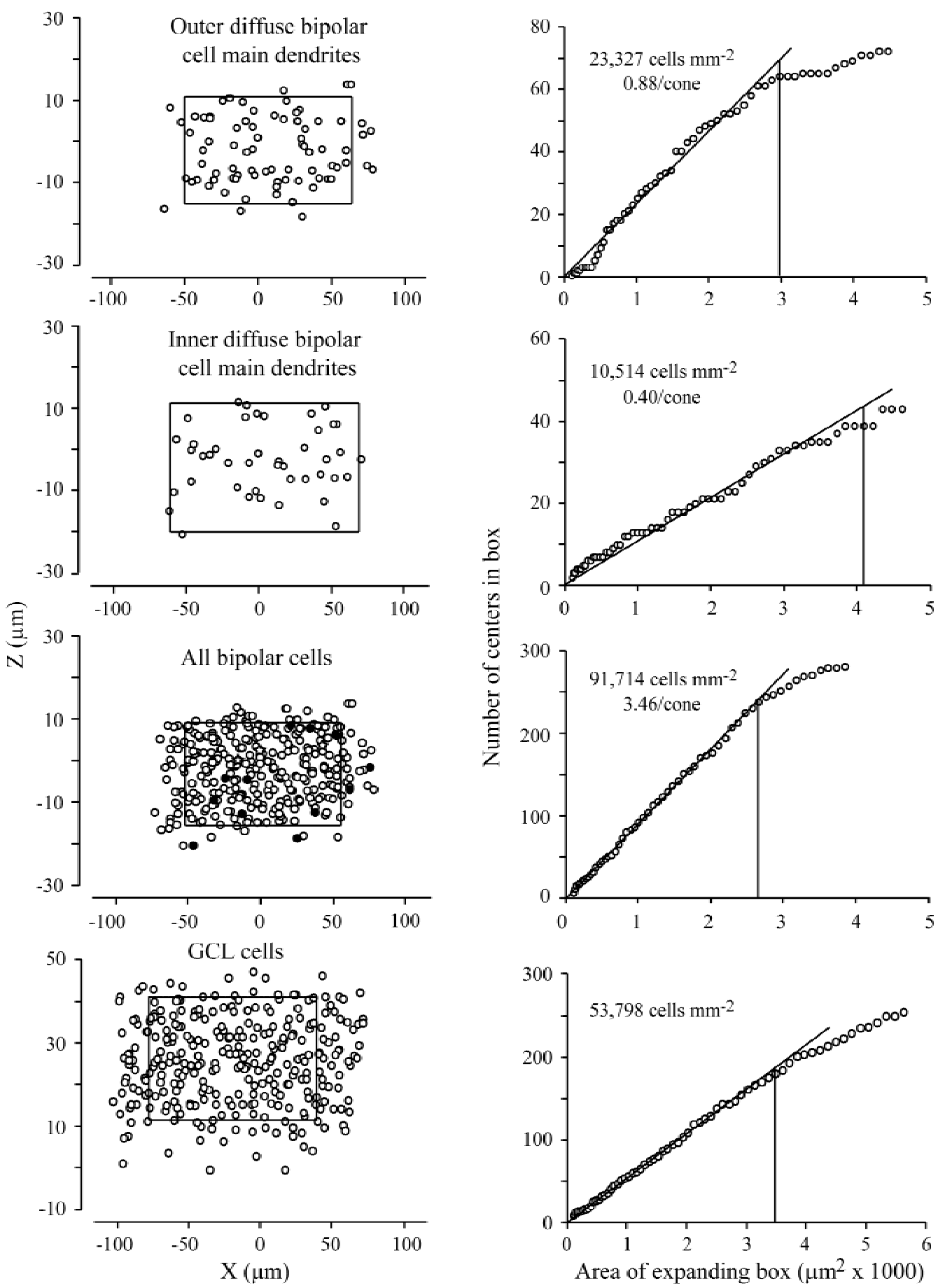

Fig. 10. Densities of outer and inner diffuse bipolar cells, All bipolar cells, and ganglion cell layer (GCL) cells. Cell arrays are shown after rotations of center coordinates as described in Fig. 3. In the All bipolar cell plot, open circles mark the somas of inner and outer midget bipolar cells and the main dendrites of inner and outer diffuse bipolar cells, filled circles mark the main dendrites of inner S-cone bipolar cells, and open stars mark the main dendrites of rod bipolar cells. The density of each array of retinal cells is computed for that cell's measurement box (cf. Fig. 4), but with two exceptions: For All bipolar cells, the calculation of the center and the aspect ratio of the box does not include the two lowest (inner S-cone bipolar) cells. Also, the GCL box is centered at $X=-19.749 \mu \mathrm{m}$, laterally

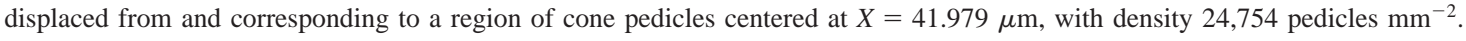

There were even fewer rod spherules and rod bipolar cells in our material, just seven and four. In addition, all seven were in the peripheral half of our patch of retina. Therefore, the rod density that we calculated, 1501 cells $\mathrm{mm}^{-2}$, applied only to the peripheral half. To obtain the density of rod bipolar cells, we measured the density of the combined array of rod and inner $\mathrm{S}$-cone bipolar cells and subtracted the density of inner S-cone bipolar cells. 


\section{Ganglion cells}

We measured 53,798 GCL cells $\mathrm{mm}^{-2}$ (Fig. 10). Removing the displaced amacrine cells, estimated at $5 \%$ in the fovea (Wässle et al., 1990), left 51,108 ganglion cells $\mathrm{mm}^{-2}$. Because of lateral displacement of ganglion cells from bipolar cells and cone pedicles, $1 \mathrm{~mm}^{2}$ at the level of the cone pedicles corresponded to $1.27 \mathrm{~mm}^{2}$ at the center of the GCL (see Materials and methods). Therefore, the estimated density of ganglion cells was 64,907 ganglion cells per square millimeter of cones, giving 2.62 ganglion cells per cone (Table 3).

\section{Discussion}

\section{Cell densities}

We computed cell densities after identifying every cell in a patch of retina. Because we were able to enumerate every cell, and because our densities were based on two-dimensional arrays of points, we avoided the complications associated with stereological methods. Rodieck (1991) did likewise with his related "density recovery method". He began by creating a spatial autocorrelation pattern by superimposing all the points around every single point in his array of retinal cells. He then computed density from the points accumulated within disks of increasing area. That method, however, required large arrays of points, the kind of data afforded by light-microscopic methods. Therefore, we developed the expanding box method in order to optimize density calculations for the smaller arrays of points afforded by electron-microscopic methods.

\section{Midget bipolar cells-the rule and the exception}

Based on tracking of connectivity in electron photomicrographs, Klug et al. (1991) described an exception to the assumption that each foveal cone contacts one inner midget bipolar cell and one outer midget bipolar cell (Kolb et al., 1969; Kolb, 1970). There and elsewhere (Klug et al., 1992; Herr et al., 2003) we have reported that $\mathrm{L}$ and $\mathrm{M}$ cones contacted their own inner midget bipolar cells, whereas $\mathrm{S}$ cones did not. By contrast, $\mathrm{S}$ cones as well as other cones contacted outer midget bipolar cells (Klug et al., 1992). From light-microscopic, immunocytochemical identification of inner bipolar cells with anti-CCK antibody and outer bipolar cells with anti-recoverin antibody, Wässle et al. (1994) used cell counts within the fovea to confirm the findings of Klug et al. From connectivity and density measurements reported here, for more cells than were initially reported by Klug et al., we confirm the finding of one outer midget bipolar cell for each cone and one inner midget bipolar cell for each $\mathrm{L} / \mathrm{M}$ cone.

The assumed, ideal picture has other exceptions as well. Some multiply-headed midget bipolar cells gather all the inner or outer midget output of two (Boycott \& Hopkins, 1991; Hopkins \& Boycott, 1992) or more cones (Polyak, 1941), but these exceptions are more common farther from the fovea. For the region centered at $575 \mu \mathrm{m}$, we found one double-headed inner midget bipolar cell out of 86 inner midget bipolar cells and no double-headed outer midget bipolar cell out of 91 outer midget bipolar cells. At a slightly greater eccentricity, 0.7-2.1 mm, Wässle et al. (1994) found four double-headed (inner and outer) midget bipolar cells out of 102 .

\section{Asymmetry in numbers of inner and outer diffuse} bipolar cells

We found 0.88 outer diffuse bipolar cells for each cone, or nearly one-for-one. From measurements of the areas of diffuse bipolar terminal footprints, Boycott and Wässle (1991) estimated densities of three types of outer diffuse bipolar cell, DB1, DB2, and DB3, in a peripheral patch of retina at 6-7 $\mathrm{mm}$. They estimated an aggregate density ratio of 1.03 outer diffuse bipolar cells per cone, in reasonably close agreement with our foveal value (Table 4).

We found considerably fewer inner diffuse bipolar cells, just 0.40 per foveal cone. (We wonder if this is the reason that inner diffuse bipolar cells were identified much later (Mariani, 1981) than outer diffuse bipolar cells (Kolb, 1970).) We found roughly half as many inner diffuse as outer diffuse bipolar cells by every observation: numbers of each in single photomicrographs (Figs. 1 $\& 2$ ), numbers of each identified solely by the location of their terminals in the IPL, numbers of each identified solely by the asymmetric/symmetric nature of their synaptic contacts with cone pedicles, and total numbers of of each identified by the latter two methods along with a third, dense versus pale (Table 2). Consistent with our finding of 1.3 (outer plus inner) diffuse bipolar cells per cone, Grünert et al. (1994) found 1.5 per cone at 4.5-mm eccentricity, and they suggested that this density ratio extended into the fovea as well.

The inner diffuse bipolar cell population is also believed to be comprised of three cell types: DB4, DB5, and DB6 (Boycott \& Wässle, 1991). Grünert et al. (1994) reported $\sim 3500$ foveal DB4 cells $\mathrm{mm}^{-2}$ at $500-\mu \mathrm{m}$ eccentricity. Assuming the same ratios of DB4:DB5:DB6 as reported by Boycott and Wässle (1991) for their peripheral patch, 2:3:1, the total density of foveal inner diffuse bipolar cells in Grünert et al. (1994) ought to have been $\sim 10,500 \mathrm{~mm}^{-2}$, identical to the 10,514 that we report (Tables 3 \& 4B).

Boycott and Wässle (1991) report an exception to this inner/ outer asymmetry for a peripheral patch of macaque retina. They found 1.13 inner diffuse bipolar cells per cone, similar to 1.03 for outer diffuse bipolar cells (Table 4B), much higher than our foveal value, and very close to one-for-one.

In macaque retina, Chichilnisky and Kalmar (2002) report receptive fields for macaque $\mathrm{ON}$ parasol ganglion cells that are 1.2 times the diameter of OFF, hence 1.44 times the area. If coverage by $\mathrm{ON}$ and $\mathrm{OFF}$ ganglion cells were equal, the density of outer parasol ganglion cells would have to be 1.44 times the density of inner parasol ganglion cells. Similarly, Dacey and Petersen (1992) report dendritic fields for human inner parasol ganglion cells that are 1.3-1.5 times the diameter of outer, hence 1.7-2.25 times the area. This inner/outer asymmetry seems to be a general feature of the alpha (or parasol in primate) ganglion cells of a wide variety of mammalian species, including rat, cat, dog, and rabbit (Table 2 of Peichl et al., 1987; Tauchi et al., 1992). This asymmetry is similar to that which we find for diffuse bipolar cells, which provide the bipolar input to parasol cells (Jacoby et al., 1996; Jacoby \& Marshak, 2000; Jacoby et al., 2000).

\section{Psychophysical evidence for asymmetry}

There is considerable psychophysical evidence consistent with greater numbers of foveal OFF than ON parasol ganglion cells. Stimuli with a rapid-ON sawtooth temporal waveform preferentially excite and adapt ON cells, whereas rapid-OFF sawtooth stimuli preferentially excite and adapt OFF cells (Kremers et al., 
Table 4. Reported retinal cell densities ${ }^{\mathrm{a}}$

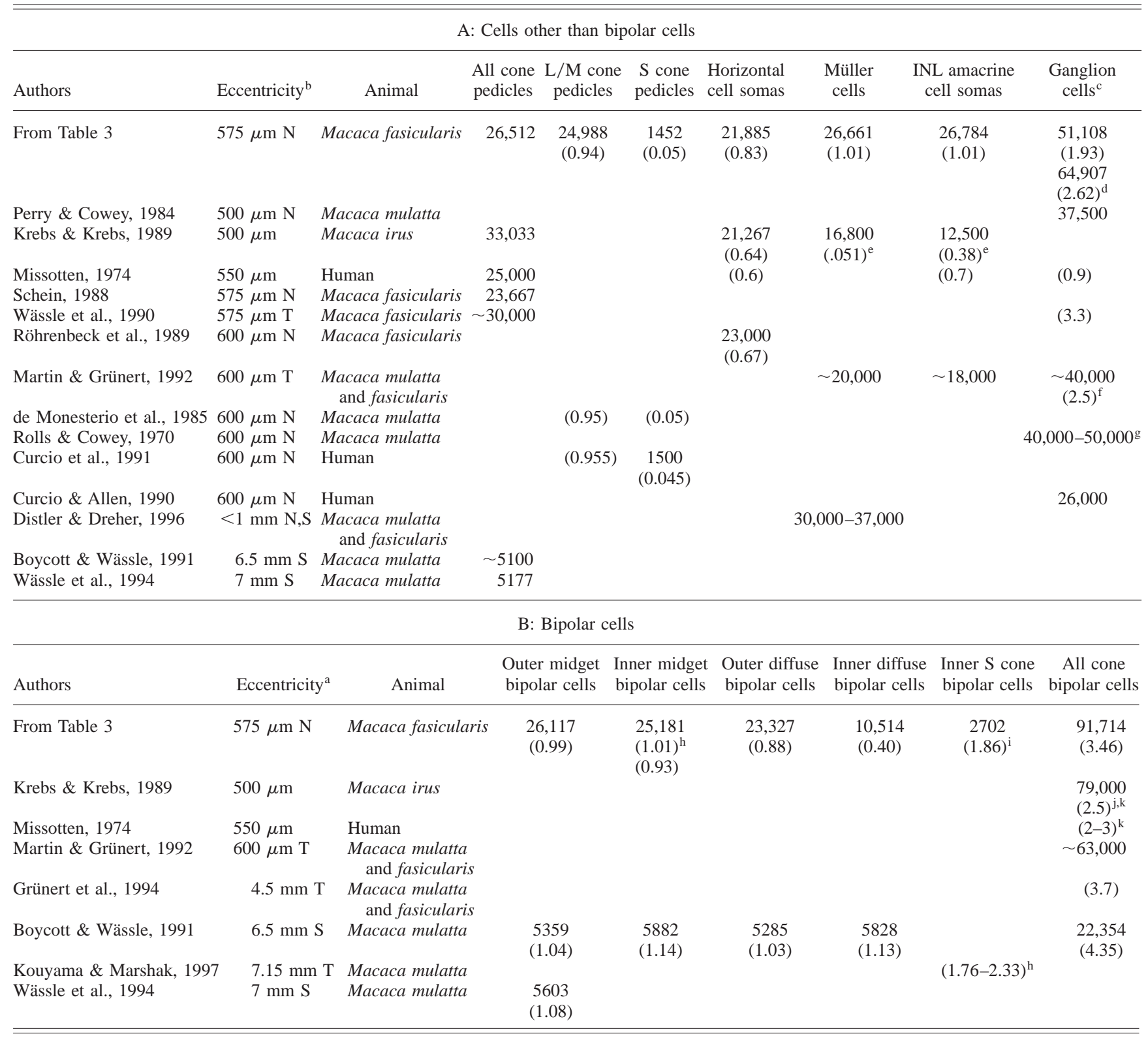

${ }^{\mathrm{a}}$ Whenever possible, the tables show both the cell density and the ratio of the density of the cell to that of cone pedicles (in parentheses). No attempt is made to compensate for variation due to differences in tissue preparation or other methodology.

${ }^{\mathrm{b}}$ The region of the retina where the measurement was taken is given as nasal $(\mathrm{N})$, temporal (T), superior (S), inferior (I), or left blank if unspecified.

${ }^{\mathrm{c}}$ Authors generally did not correct for retinal areal magnification.

${ }^{\mathrm{d}}$ This ganglion cell density is corrected for retinal areal magnification.

${ }^{e}$ Krebs and Krebs (1989) counted cells in tangential sections from three animals and incorrectly assumed that Müller and amacrine cells formed a monolayer. The table shows averages.

${ }^{\mathrm{f}}$ Martin and Grünert (1992) assumed 2.5 for the density ratio of ganglion cells to cones.

${ }^{g}$ The density of ganglion cells in Rolls and Cowey (1970) is expressed in cells deg ${ }^{-2}$. See Schein (1988) for transformation to cells mm ${ }^{-2}$.

${ }^{\mathrm{h}}$ This density ratio is for inner midget bipolar cells to L/M-cone pedicles (not All cone pedicles).

${ }^{\mathrm{i}}$ This density ratio is for inner S-cone bipolar cells to S-cone pedicles (not All cone pedicles).

${ }^{\mathrm{j}}$ Krebs and Krebs (1989) accounted for all bipolar cells by counting soma, main dendrites, and axons in a single section.

${ }^{\mathrm{k}}$ With few rod bipolar cells in the fovea, reported values for all bipolar cells are shown in the column giving cone bipolar cells.

1993). Such sawtooth stimuli have been used to show that human observers are more sensitive to luminance decrement than to luminance increment (Patel \& Jones, 1968; Krauskopf, 1980; Bowen et al., 1989, 1992).

This asymmetric sensitivity to increments and decrements is likely to be retinal in origin, since it is monocular (Anstis, 1967).
Within the retina, this asymmetry appears to be associated with the diffuse bipolar/parasol ganglion cell pathway rather than the midget bipolar/midget ganglion cell pathway for the following reasons: (1) chromatic sawtooth stimuli reveal no such asymmetry (DeMarco et al., 1994); (2) diffuse/parasol circuits are more sensitive than midget circuits to the rapidly changing luminance used in the 
sawtooth stimuli; (3) the receptive fields of the effect are much larger than that of the midget cells (Anstis \& Harris, 1987); and (4) the high contrast sensitivity of individual parasol — but not midgetganglion cells is similar to human contrast sensitivity as studied in these experiments (Kremers et al., 1993).

Individual $\mathrm{ON}$ and OFF ganglion cells in macaque are equally sensitive to increments and decrements, respectively, so the psychophysical asymmetry appears to reflect a greater density of outer than inner parasol ganglion cells, not the properties of individual cells (Kremers et al., 1991, 1993; Benardete \& Kaplan, 1999; but see Chichilnisky \& Kalmar, 2002). Consistent with this interpretation, human observers exhibit finer spatial resolution for light decrements than for light increments (Zemon et al., 1988).

The limited number of invaginating central elements postsynaptic to foveal cone pedicles may be the reason why there are fewer foveal inner than outer diffuse bipolar cells per cone. Specifically, foveal cone pedicles are presynaptic to slightly more than 20 central elements (Chun et al., 1996). Eighty percent of these central elements $(\sim 16)$ are provided by an inner midget bipolar cell, leaving just 20\% ( 4) for inner diffuse bipolar cells (Herr et al., 2003; see also Kolb, 1970 and Boycott \& Hopkins, 1991). With so few central-element slots left, some putative inner diffuse bipolar cells may not be able to fulfill their quota of central elements (Hopkins \& Boycott, 1995, 1996, 1997; Calkins et al., 1996) and may not differentiate into or survive as inner diffuse bipolar cells. No such limitation applies to the basal contacts made by foveal cone pedicles onto outer diffuse bipolar cells. By contrast, in peripheral retina, the cone pedicles are presynaptic to more than 90 central elements, with a large number available for inner diffuse bipolar cells (Chun et al., 1996). Perhaps this finding explains why the peripheral cone pedicles can accommodate as many inner as outer diffuse bipolar cells (Boycott \& Wässle, 1991). Correspondingly, psychophysical asymmetries appear to be stronger in the fovea than in the periphery (Arnold \& Anstis, 1993).

\section{Integer density ratios}

Taken one at a time, each cell density or cell-density ratio reported here was consistent with that in some other report (Table 4). For purposes of comparison among different groups of cells, the density ratios in this paper had these advantages over previous ones: All ratios were obtained from a single block of retina, and different cell types were all processed, photographed, and analyzed identically. The measurements were all from the same eccentricity, indeed, from the same patch of fovea. We identified every cell in the patch. Based on ultrastructure, we were able to assign bipolar cells to different groups. Finally, we were careful to take into account lateral displacement and areal magnification. As a result of these advantages, our set of cell-density ratios creates a qualitatively new picture.

We find that there is one inner midget bipolar cell for each $\mathrm{L}$ and $\mathrm{M}$ cone and one outer midget bipolar cell for each $\mathrm{L}, \mathrm{M}$, and $\mathrm{S}$ cone. In the fovea there is one midget ganglion cell for each midget bipolar cell (Polyak 1941; Boycott \& Dowling, 1969; Kolb \& DeKorver, 1991; Klug et al., 1993; Calkins et al., 1994), so there must be one inner midget ganglion cell for each $\mathrm{L}$ and $\mathrm{M}$ cone and one outer midget ganglion cells for each L, M, and $\mathrm{S}$ cone. Therefore, rigorously in some cases and nearly so in others, for each foveal $\mathrm{L} / \mathrm{M}$ cone there is one inner midget bipolar cell, one outer midget bipolar cell, one outer diffuse bipolar cell, one horizontal cell, one Müller cell, one INL amacrine cell, one inner midget ganglion cell, and one outer midget ganglion cell (Table 3). In the periphery, at 6-7 mm eccentricity, where there is still one outer midget bipolar cell, one inner midget bipolar cell, and one outer diffuse bipolar cell for each cone, there is even one inner diffuse cell for each cone (Table 4B) (Boycott \& Wässle, 1991; Wässle et al., 1994).

There are also integer ratios of cell density in foveal S-cone circuits. For each foveal S cone, there are one outer midget bipolar cell and its midget ganglion cell (Klug et al., 1992, 1993) and two inner S-cone bipolar cells (Kouyama \& Marshak, 1997; Herr et al., 2003). Herr et al. (2003) showed that there are also two small (blue-ON/yellow-OFF) bistratified ganglion cells (Dacey \& Lee, 1994; Calkins et al., 1998) for each S cone.

Inner diffuse bipolar cells and displaced amacrine cells appear to deviate from this integer pattern. In addition, we found fewer ganglion cells, a total of 2.62 per cone, than bipolar cells, 3.4 per cone. Removal of inner and outer midget ganglion cells and small bistratified ganglion cells from our measured density ratio of 2.62 ganglion cells per cone left just 0.57 (or 22\%) of non-midget ganglion cells per cone (Fig. 11A). These non-midget ganglion cells may be presumed to be parasol and retinotectal (Rodieck, 1998). If their numbers were equal, then each group would comprise $0.29 / 2.62=11 \%$ of foveal ganglion cells, in agreement with actual values (Perry et al., 1984; Perry \& Cowey, 1984). Moreover, there were many fewer $(0.57 /$ cone $)$ of these non-midget ganglion cells than diffuse bipolar cells (1.31/cone) (Fig. 11B). Therefore, these non-midget types of ganglion cell also deviate from the integer pattern.

\section{Columnar units}

A number of investigators have suggested that the retina may be described as composed of "columns" or clones of cells. Reichenbach and his colleagues (Reichenbach et al., 1994; Reichenbach \& Robinson, 1995) focus on the Müller cell as providing scaffolding with which a nearly constant number of retinal cells are associated. Since we find one Müller cell for each cone (see also Burris et al., 2002), the integer density ratios that we describe for foveal neurons per cone are also integer density ratios of foveal neurons per Müller cell.

Along the same lines, by use of chimeric embryos to identify retinal clones at an early stage of retinal development, Williams and Goldowitz (1992) reported single radial clones in mice, all of which were comprised of cells in ratios identical to those in the mature retina. Reese and Tan (1998) and Reese et al. (1999), taking advantage of $X$ chromosome inactivation in transgenic mice with the lacZ reporter gene on one $\mathrm{X}$ chromosome to mark progenitors at an early stage of development, also found a radial, columnar disposition of clone progeny and proportions of cells that were similar from clone to clone.

In macaque foveal retina, we find that a cone (or Müller cell) and those cells in integer density ratios total $\sim 9$ cells, to which we add a small number of non-midget ganglion cells and displaced amacrine cells. Because the number of cell divisions that produce such a retinal clone is small (Rapaport et al., 1996), the number of cells of a given group may be just one or two, with later differentiation within each group into specific cell types. For example, we find close to one outer diffuse bipolar cell per foveal cone, but this group of cells is comprised of three cell types, DB1, DB2, and DB3 (Boycott \& Wässle, 1991). Similarly, midget bipolar cells could be divided into subtypes based on the center-cone type, S, M, or L, and the 

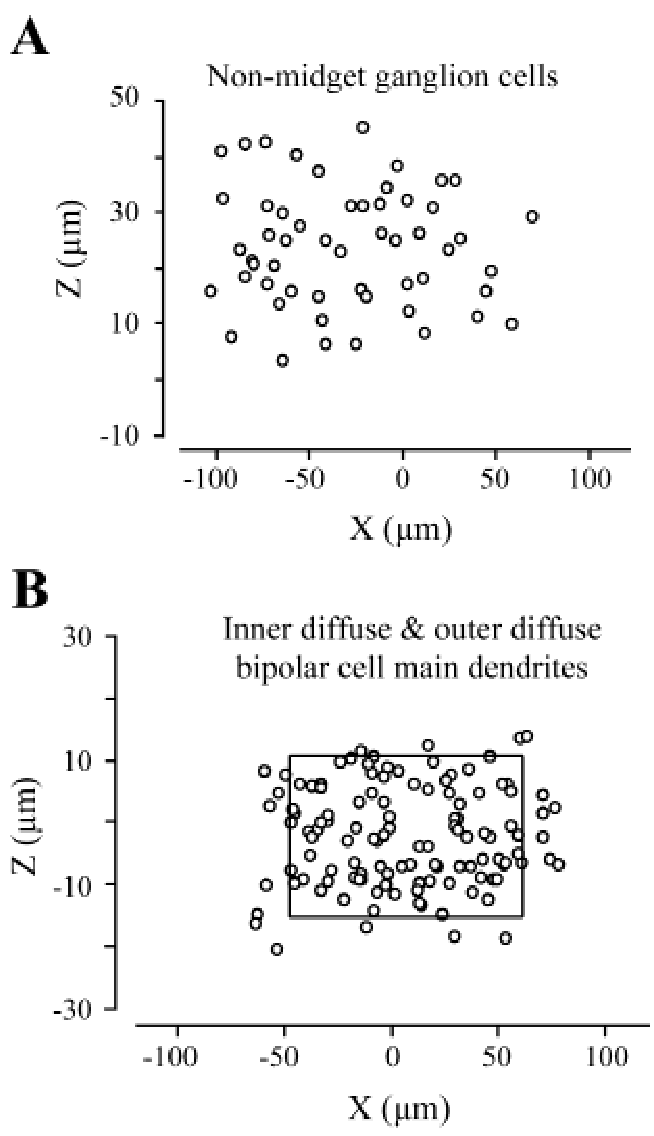

Fig. 11. Visual comparison of arrays. A: Non-midget ganglion cells. Five percent of all GCL cells in Fig. 9 were removed randomly to discount displaced amacrine cells (Wässle al., 1990), and 78\% of the remaining (ganglion) cells (see below) were removed randomly to account for the populations of midget and small bistratified ganglion cells. The remaining $22 \%$, shown here, are the non-midget ganglion cells, presumably parasol and retinotectal, which are contacted by diffuse bipolar cells. To represent the effect of magnification from diffuse bipolar cells to these ganglion cells, the horizontal (radial) and vertical (circumferential) axes of this array are compressed by 1.15 and 1.11, respectively. The $78 \%$ figure was obtained as follows: For each $\mathrm{L}$ and $\mathrm{M}$ cone, there are two (one outer and one inner) midget ganglion cells; $\mathrm{L}$ and $\mathrm{M}$ cones constitute $95 \%$ of the cones, so they account for $(0.95 \times 2) \mathrm{GC}$ per cone $=1.9 \mathrm{GC}$ per cone. For each $\mathrm{S}$ cone, there are three (one outer midget and two small bistratified) ganglion cells; $\mathrm{S}$ cones constitute $5 \%$ of the cones, so they account for $(0.05 \times 3) \mathrm{GC}$ per cone $=0.15 \mathrm{GC}$ per cone. Combined, these populations account for $2.05 \mathrm{GC}$ per cone, or $78 \%$ of the total of $2.62 \mathrm{GC}$ per cone, leaving 0.57 non-midget GC per cone, or $22 \%$ of the total number of ganglion cells. B: Combined inner diffuse bipolar cells and outer diffuse bipolar cells, both from Fig. 10.

density of each specific type of INL amacrine and horizontal cell (Kolb et al., 1980; Kolb et al., 1994; Ahnelt \& Kolb, 1994; MacNeil \& Masland, 1998) is much less than that of cones.

The composition of cells within a column or clone varies with eccentricity, as rods and rod-related circuits enter the picture and as cone convergence increases. Nonetheless, these integer density ratios may still hold into the periphery for some cells, including inner and outer midget bipolar cells, inner and outer diffuse bipolar cells, and inner S-cone bipolar cells (Table 4).

\section{Acknowledgments}

We thank Dr. Yoshihiko Tsukamoto, Patricia Masarachia, and Sally Shrom for preparing the electronic-microscopic (EM) material. We also thank Kazuki Uema and Lisa Travis for printing. Portions of this work were previously presented in abstract form in Klug et al. (1991) and in Burris et al. (1999). The Müller cell material is also described in Burris et al. (2002). The work was supported by NIH grants EY11153 (S.S.) and EY08124 (P.S.) and by the UCLA Academic Senate (S.S.).

\section{References}

Ahnelt, P. \& KolB, H. (1994). Horizontal cells and cone photoreceptors in primate retina: A Golgi-light microscopic study of spectral connectivity. Journal of Comparative Neurology 343, 387-405.

Anstis, S.M. (1967). Visual adaptation to gradual change of intensity. Science 155, 710-712.

ANSTIS, S. \& HaRRIS, J. (1987). Magnification factor for adaptation of a visual transient mechanism. Journal of the Optical Society of America 8, 1688-1698.

Arnold, K. \& Anstis, S. (1993). Properties of the visual channels that underlie adaptation to gradual change of luminance. Vision Research 33, 47-54.

Benardete, E.A. \& Kaplan, E. (1999). The dynamics of primate M retinal ganglion cells. Visual Neuroscience 16, 355-368.

Bowen, R.W., Pokorny, J. \& Smith, V.C. (1989). Sawtooth contrast sensitivity: Decrements have the edge. Vision Research 29, 1501-1509.

Bowen, R.W., Pokorny, J., Smith, V.C. \& Fowler, M.A. (1992). Sawtooth contrast sensitivity: Effects of mean illuminance and low temporal frequencies. Vision Research 32, 1239-1247.

BoycotT, B.B. \& Dowling, J.E. (1969). Organization of the primate retina: Light microscopy. Philosophical Transactions of the Royal Society B (London) 255, 109-184.

Boycotт, B.B. \& Hopkins, J.M. (1991). Cone bipolar cells and cone synapses in the primate retina. Visual Neuroscience 7, 49-60.

BoycotT, B.B. \& WässLE, H. (1991). Morphological classification of bipolar cells of the primate retina. European Journal of Neuroscience $\mathbf{3}$, $1069-1088$.

Boycott, B.B. \& Hopkins, J.M. (1993). Cone synapses of a flat diffuse cone bipolar cell in the primate retina. Journal of Neurocytology 22, $765-778$.

Burris, C.J., Sterling, P. \& Schein, S. (1999). One Müller cell per foveal cone in macaque monkey. Investigative Ophthalmology and Visual Science 40, S238.

Burris, C.J., Klug, K., Tran Ngo, I., Sterling, P. \& Schein, S. (2002). How Müller glial cells in macaque fovea coat and isolate the synaptic terminals of cone photoreceptors. Journal of Comparative Neurology. 453, 100-111.

Calkins, D.J., Schein, S.J., Tsukamoto, Y. \& Sterling, P. (1994). M and $\mathrm{L}$ cones in macaque fovea connect to midget ganglion cells by different numbers of excitatory synapses. Nature $\mathbf{3 7 1 4}, 70-72$.

Calkins, D.J., Tsukamoto, Y. \& Sterling, P. (1996). Foveal cones form basal as well as invaginating junctions with diffuse ON bipolar cells. Vision Research 36, 3373-3381.

Calkins, D.J., Tsukamoto, Y. \& Sterling, P. (1998). Microcircuitry and mosaic of a blue-yellow ganglion cell in the primate retina. Journal of Neuroscience 18, 3373-3385.

Chichilnisky, E.J. \& Kalmar, R.S. (2002). Functional asymmetries in $\mathrm{ON}$ and OFF ganglion cells of primate retina. Journal of Neuroscience 22, 2737-2747.

Chun, M.H., Grünert, U., Martin, P.R. \& Wässle, H. (1996). The synaptic complex of cones in the fovea and in the periphery of the macaque monkey retina. Vision Research 36, 3383-3395.

Curcio, C.A. \& Allen, K.A. (1990). Topography of ganglion cells in human retina. Journal of Comparative Neurology 300, 5-25.

Curcio, C.A., Allen, K.A., Sloan, K.R., Lerea, C.L., Hurley, J.B., Klock, I.B. \& Milam, A.H. (1991). Distribution and morphology of human cone photoreceptors stained with anti-blue opsin. Journal of Comparative Neurology 312, 610-624.

DACEY, D.M. (1993a). Morphology of a small-field bistratified ganglion cell type in the macaque and human retina. Visual Neuroscience 10, 1081-1098.

DACEY, D.M. (1993b). The mosaic of midget ganglion cells in the human retina. Journal of Neuroscience 13, 5334-5355. 
Dacey, D.M. \& Petersen, M.R. (1992). Dendritic field size and morphology of midget and parasol ganglion cells of the human retina. Proceedings of the National Academy of Sciences of the U.S.A. 89, 9666-9670.

DACEY, D.M. \& LEe, B.B. (1994). The 'blue-ON' opponent pathway in primate retina originates from a distinct bistratified ganglion cell type. Nature 367, 731-735.

DeMarco, P.J., JR., Smith, V.C. \& Pokorny, J. (1994). Effect of sawtooth polarity on chromatic and luminance detection. Visual Neuroscience 11, 491-499.

de Monasterio, F.M., McCrane, E.P., Newlander, J.K. \& Schein, S.J. (1985). Density profile of blue-sensitive cones along the horizontal meridian of macaque retina. Investigative Ophthalmology and Visual Science 26, 289-302.

Distler, C. \& Dreher, Z. (1996). Glia cells of the monkey retina II. Müller cells. Vision Research 36, 2381-2394.

Famiglietti, E.V. \& Kolb, H. (1976). Structural basis for ON- and OFF-center responses in retinal ganglion cells. Science 194, 193-195.

Grünert, U., Martin, P.R. \& Wässle, H. (1994). Immunocytochemical analysis of bipolar cells in the macaque monkey retina. Journal of Comparative Neurology 348, 607-627.

Herr, S.S., Klug, K., Sterling, P. \& Schein, S.J. (2003). Inner S-cone bipolar cells provide all of the central elements for $\mathrm{S}$ cones in macaque retina. Journal of Comparative Neurology 457, 185-201.

Hopkins, J.M. \& BoycotT, B.B. (1992). Synaptic contacts of a two-cone flat bipolar cell in a primate retina. Visual Neuroscience 8, 379-384.

Hopkins, J.M. \& BoycotT, B.B. (1995). Synapses between cones and diffuse bipolar cells of a primate retina. Journal of Neurocytology $\mathbf{2 4}$, 680-694.

Hopkins, J.M. \& BoycotT, B.B. (1996). The cone synapses of DB1 diffuse, DB6 diffuse and invaginating midget, bipolar cells of a primate retina. Journal of Neurocytology 25, 381-390.

Hopkins, J.M. \& BoycotT, B.B. (1997). The cone synapses of cone bipolar cells of primate retina. Journal of Neurocytology 26, 313-325.

JACOBY, R.A., \& MARshaK, D.W. (2000). Synaptic connections of DB3 diffuse bipolar cell axons in macaque retina. Journal of Comparative Neurology 416, 19-29.

Jacoby, R.A., Stafford, D., Kouyama, N., \& MarshaK, D.W. (1996). Synaptic inputs to $\mathrm{ON}$ parasol ganglion cells in the primate retina. Journal of Neuroscience 16, 8041-8056.

Jacoby, R.A., Wiechmann, A.F., Amara, S.G., Leighton, B.H. \& MarSHAK, D.W. (2000). Diffuse bipolar cells provide input to OFF parasol ganglion cells in the macaque retina. Journal of Comparative Neurology 416, 6-18.

Klug, K., Schein, S.J., Masarachia, P., Sterling, P. \& Tsukamoto, Y. (1991). Identification of all cells in a small patch of fovea of macaque retina. Abstracts of the Society for Neuroscience 17, S1375.

Klug, K., Tiv, N., Tsukamoto, Y., Sterling, P. \& Schein, S.J. (1992). Blue cones contact Off-midget bipolar cells. Abstracts of the Society for Neuroscience 18, S838.

Klug, K., Tsukamoto, Y., Sterling, P. \& Schein, S.J. (1993). Blue cone off-midget ganglion cells in macaque. Investigative Ophthalmology and Visual Science 34, S986.

Kolb, H. (1970). Organization of the outer plexiform layer of the primate retina: Electron microscopy of Golgi-impregnated cells. Philosophical Transactions of the Royal Society B (London) 258, 261-283.

Kolb, H., BoycotT, B. \& Dowling, J.E. (1969). A second type of midget bipolar cell in the primate retina. Philosophical Transactions of the Royal Society $B$ (London) 255, 177-184.

Kolb, H. \& DeKorver, L. (1991). Midget ganglion cells of the parafovea of the human retina: A study by electron microscopy and serial section reconstructions. Journal of Comparative Neurology 303, 617-636.

Kolb, H., Fernandez, E., Schouten, J., Ahnelt, P., Linberg, K.A. \& FISHER, S.K. (1994). Are there three types of horizontal cell in the human retina? Journal of Comparative Neurology 343, 370-386.

Kolb, H., Mariani, A. \& Gallego, A. (1980). A second type of horizontal cell in the monkey retina. Journal of Comparative Neurology 189, 31-44.

Koontz, M.A. \& Hendrickson, A.E. (1987). Stratified distribution of synapses in the inner plexiform layer of primate retina. Journal of Comparative Neurology 263, 581-592.

Kouyama, N. \& MarshaK, D.W. (1992). Bipolar cells specific for blue cones in the macaque retina. Journal of Neuroscience 12, 1233-1252.

Kouyama, N. \& MarshaK, D.W. (1997). The topographical relationship between two neuronal mosaics in the short wavelength-sensitive system of the primate retina. Visual Neuroscience 14, 159-167.
Krauskopf, J. (1980). Discrimination and detection of changes in luminance. Vision Research 20, 671-677.

KreBS, W. \& KreBS, I.P. (1989). Quantitative morphology of the central fovea in the primate retina. American Journal of Anatomy 184, 225-236.

Kremers, J., Lee, B.B., Pokorny, J. \& Smith, V.C. (1991). The response of macaque retinal ganglion cells to complex temporal waveforms. In From Pigments to Perception: Advances in Understanding Visual Processes, Valberg, A. \& Lee, B.B., ed. pp. 173-176. New York: Plenum Press.

Kremers, J., Lee, B.B., Pokorny, J. \& Smith, V.C. (1993). Responses of macaque ganglion cells and human observers to compound periodic waveforms. Vision Research 33, 1997-2011.

MacNeIl, M.A. \& Masland, R.H. (1998). Extreme diversity among amacrine cells: implications for function. Neuron 20, 971-982.

Mariani, A.P. (1981). A diffuse, invaginating cone bipolar cell in primate retina. Journal of Comparative Neurology 197, 661-671.

MARIANI, A.P. (1983). Giant bistratified bipolar cells in the monkey retina. Anatomical Record 206, 215-220.

MARIANI, A.P. (1984). Bipolar cells in monkey retina selective for the cones likely to be blue-sensitive. Nature 308, 184-186.

Martin, P.R. \& GRÜNERT, U. (1992). Spatial density and immunoreactivity of bipolar cells in the Macaque monkey retina. Journal of Comparative Neurology 323, 269-287.

Missotten, L. (1974). Estimation of the ratio of cones to neurons in the fovea of the human retina. Investigative Ophthalmology 13, 1045-1049.

Nelson, R., FAmiglietti, E.V. \& Kolb, H. (1978). Intracellular staining reveals different levels of stratification for on- and off-center ganglion cells in cat retina. Journal of Neurophysiology 41, 472-483.

PAtel, A.S. \& Jones, R.W. (1968). Increment and decrement visual thresholds. Journal of the Optical Society of America 58, 696-699.

Peichl, L., Отт, H. \& Bоyсотт, B.B. (1987). Alpha ganglion cells in mammalian retinae. Proceedings of the Royal Society B (London) 231, 169-197.

Perry, V.H. \& Cowey, A. (1984). Retinal ganglion cells that project to the superior colliculus and pretectum in the macaque monkey. Neuroscience 12, 1125-1137.

Perry, V.H., Oehler, R. \& Cowey, A. (1984). Retinal ganglion cells that project to the dorsal lateral geniculate nucleus in the macaque monkey. Neuroscience 12, 1101-1123.

Polyak, S.L. (1941). The Retina. Chicago, Illinois: University of Chicago Press.

RAPAPORT, D.H., RAKIC, P. \& LaVAIL, M.M. (1996). Spatiotemporal gradients of cell genesis in the primate retina. Perspectives on Developmental Neurobiology 3, 147-159.

Raviola, E. \& Gilula, N.B. (1975). Intramembrane organization of specialized contacts in the outer plexiform layer of the retina. A freeze-fracture study in monkeys and rabbits. Journal of Cell Biology 65, 192-222.

ReEse, B.E. \& TAN, S.S. (1998). Clonal boundary analysis in the developing retina using $\mathrm{X}$-inactivation transgenic mosaic mice. Seminars in Cell and Developmental Biology 9, 285-292.

Reese, B.E., Necessary, B.D., Tam, P.P., Faulkner-Jones, B. \& Tan, S.S. (1999). Clonal expansion and cell dispersion in the developing mouse retina. European Journal of Neuroscience 11, 2965-2978.

Reichenbach, A. \& Robinson, S.R. (1995). Phylogenetic constraints on retinal organization and development. Progress in Retinal Eye Research 15, 139-171.

Reichenbach, A., Ziegert, M., Schnitzer, J., Pritz-Hohmeier, S., Schaaf, P., Schober, W. \& Schneider, H. (1994). Development of the rabbit retina. V. The question of 'columnar units'. Brain Research. Developmental Brain Research 79, 72-84.

RoDIECK, R.W. (1991). The density recovery profile: A method for the analysis of points in the plane applicable to retinal studies. Visual Neuroscience 6, 95-111.

Rodieck, R.W. (1998). The First Steps in Seeing. Sunderland, Massachusetts: Sinauer Associates. pp. 255-265.

RöhrenbecK, J., WÄssle, H. \& BoycotT, B.B. (1989). Horizontal cells in the monkey retina: Immunocytochemical staining with antibodies against calcium binding proteins. European Journal of Neuroscience 1, 407-420.

Rolls, E.T. \& Cowey, A. (1970). Topography of the retina and striate cortex and its relationship to visual acuity in rhesus monkeys and squirrel monkeys. Experimental Brain Research 10, 298-310.

ScheIN, S.J. (1988). Anatomy of macaque fovea and spatial densities of neurons in foveal representation. Journal of Comparative Neurology 269, 479-505. 
Sıöstrand, J., Olsson, V., Popovic, Z. \& Conradi, N. (1999). Quantitative estimations of foveal and extra-foveal retinal circuitry in humans. Vision Research 18, 2987-2998.

Smith, R.G. (1987). Montage: A system for three-dimensional reconstruction by personal computer. Journal of Neuroscience Methods 21, $55-69$.

Tauchi, M., Morigiwa, K. \& Fukuda, Y. (1992). Morphological comparison between outer and inner ramifying alpha cells of the albino rat retina. Experimental Brain Research 88, 67-77.

Tsukamoto, Y., Masarachia, P., Schein, S.J. \& Sterling, P. (1992). Gap junctions between the pedicles of macaque foveal cones. Vision Research 10, 1809-1815.

Vardi, N., Morigiwa, K., Wang, T.-L., Shi, Y.-J. \& Sterling, P. (1998). Neurochemistry of the mammalian cone 'synaptic complex'. Vision Research 38, 1359-1369.

Vardi, N., Duvoisin, R., Wu, G. \& Sterling, P. (2000). Localization of
mGluR6 to dendrites of ON bipolar cells in primate retina. Journal of Comparative Neurology 423, 402-412.

Wässle, H., Grünert, U., Röhrenbeck, J. \& Boycott, B.B. (1990). Retinal ganglion cell density and cortical magnification factor in the primate. Vision Research 30, 1897-1911.

Wässle, H., Grünert, U., Martin, P.R. \& Boycott, B.B. (1994). Immunocytochemical characterization and spatial distribution of midget bipolar cells in the Macaque monkey retina. Vision Research 34, 561-579.

Williams, R.W. \& Goldowitz, D. (1992). Structure of clonal and polyclonal cell arrays in chimeric mouse retina. Proceedings of the National Academy of Sciences of the U.S.A. 89, 1184-1188.

Zemon, V., Gordon, J. \& Welch, J. (1988). Asymmetries in ON and OFF visual pathways of humans revealed using contrast-evoked cortical potentials. Visual Neuroscience 1, 145-150. 